\title{
A Review on Locomotor Training after Spinal Cord Injury: Reorganization of Spinal Neuronal Circuits and Recovery of Motor Function
}

\author{
Andrew C. Smith ${ }^{1}$ and Maria Knikou ${ }^{2,3}$ \\ ${ }^{1}$ Interdepartmental Neuroscience Program, Northwestern University, Chicago, IL 60611, USA \\ ${ }^{2}$ The Graduate Center, City University of New York, New York, NY 10016, USA \\ ${ }^{3}$ Department of Physical Therapy, College of Staten Island, City University of New York, Staten Island, NY 10314, USA
}

Correspondence should be addressed to Maria Knikou; maria.knikou@csi.cuny.edu

Received 8 December 2015; Accepted 20 April 2016

Academic Editor: Alain Frigon

Copyright (C) 2016 A. C. Smith and M. Knikou. This is an open access article distributed under the Creative Commons Attribution License, which permits unrestricted use, distribution, and reproduction in any medium, provided the original work is properly cited.

Locomotor training is a classic rehabilitation approach utilized with the aim of improving sensorimotor function and walking ability in people with spinal cord injury (SCI). Recent studies have provided strong evidence that locomotor training of persons with clinically complete, motor complete, or motor incomplete SCI induces functional reorganization of spinal neuronal networks at multisegmental levels at rest and during assisted stepping. This neuronal reorganization coincides with improvements in motor function and decreased muscle cocontractions. In this review, we will discuss the manner in which spinal neuronal circuits are impaired and the evidence surrounding plasticity of neuronal activity after locomotor training in people with SCI. We conclude that we need to better understand the physiological changes underlying locomotor training, use physiological signals to probe recovery over the course of training, and utilize established and contemporary interventions simultaneously in larger scale research studies. Furthermore, the focus of our research questions needs to change from feasibility and efficacy to the following: what are the physiological mechanisms that make it work and for whom? The aforementioned will enable the scientific and clinical community to develop more effective rehabilitation protocols maximizing sensorimotor function recovery in people with SCI.

\section{Introduction}

There are more than 250,000 persons living with spinal cord injury (SCI) in the United States and several million worldwide. Injuries of the spinal cord occur mostly in young adults who then require life-long healthcare. The impaired function of spinal circuitry, the impaired processing of afferent input by the spinal circuits, and the decline in transmission of uninjured fibers are clear markers of the central nervous system's (CNS) pathophysiological state after SCI [1-5].

The understanding of spinal control of locomotion has improved significantly since the times of Thomas Graham Brown and Sir Charles Sherrington [6-8]. Complex models are currently developed to address the function of the spinal networks that give genesis to single limb and bilateral right-left neuronal interactions $[9,10]$, as well as their reorganization abilities following locomotor training in animal preparations [11]. Based on the observations on the spinal neural control of locomotion and recovery of locomotion in spinalized animals, body weight support (BWS) on a treadmill with as-needed manual assistance by therapists [12, 13] and BWS on a treadmill with robot-driven leg assistance [14] are utilized to improve locomotor ability of these patients. In this review, we will provide an in-depth discussion about the manner in which spinal neuronal circuits are impaired after SCI, how they reorganize after locomotor training, the possible neurophysiological mechanisms underlying such reorganization, and the functional consequences of locomotor-training-mediated neuronal plasticity. 


\section{Neuromodulation as a Window of CNS Function}

Representative examples of neuronal activity modulation, recorded through surface electromyography (EMG) upon peripheral skin/nerve or transcortical stimulation, while walking in humans are found in three examples: the Hoffmann $(\mathrm{H})$ reflex, motor evoked potentials (MEPs), and the polysynaptic flexor reflex. First, the H-reflex, which presents the spinal part of the stretch reflex bypassing the muscle spindle and the fusimotor activity that may influence the sensitivity of the Ia afferents, is a powerful tool to probe the efficacy of Ia afferents to monosynaptically depolarize alpha motoneurons, the excitability state of spinal interneuronal circuits/ pathways, and spinal integration of sensory afferent feedback [15]. Second, MEPs, which are the result of spinal motoneuron activation following single-pulse transcranial magnetic stimulation (TMS), can be used to assess corticospinal tract excitability while walking in humans [16]. Third, stimulation of the skin at varying multiples of perceptual threshold of the foot or a pure sensory nerve (sural) can evoke short-latency, middle latency, or even long-latency responses in flexors and extensors that have specific regulatory effects on locomotion [17].

In healthy humans, while stepping on a motorized treadmill, the soleus H-reflex amplitude increases progressively from midstance to late stance, decreases significantly at stance-to-swing transition, and remains depressed during the swing phase of gait (Figure 1(a)) regardless of the BWS level [18]. A gradually increasing $\mathrm{H}$-reflex amplitude towards the end of the swing phase in healthy humans has also been reported (see [19, Figure 31]). A similar modulation pattern is also exhibited by the soleus MEP while walking. It increases progressively from early stance to midstance, reaching maximal amplitude at late stance, and is completely abolished during the swing phase with a gradually increasing MEP excitability at swing-to-stance transition (Figure 1(a)) regardless of the BWS level $[16,20]$. Further, the short-latency tibialis anterior (TA) flexor reflex, evoked following innocuous stimulation of the skin over the medial arch of the foot, increases at heel contact, progressively decreases during the stance phase, and then increases throughout the swing phase in healthy humans while stepping on a motorized treadmill (Figures 1(c) and 1(d)), a pattern similar to that observed for the TA MEP (Figures $1(\mathrm{c})$ and $1(\mathrm{~d}))[16,21]$.

2.1. Spinal Reflexes and MEP Modulation. The amplitude modulation of soleus H-reflex, soleus MEP, and shortlatency TA flexor reflex occurs largely in parallel with that of homonymous EMG activity [16, 21]. Because the soleus H-reflex remains depressed during the swing phase upon voluntary activation of the triceps surae, it is modulated in a similar manner to that observed while walking in absence of weight-bearing upon unilateral rhythmic leg movements, and the soleus MEP facilitation at swing-to-stance transition coincides with quiescent homonymous EMG [16, 22, 23], modulation of the soleus H-reflex and soleus MEP while walking cannot not be regarded simply as a sole reflection of background excitability changes of the motoneuron pool.
The soleus H-reflex amplitude modulation while walking can be partially ascribed to (1) presynaptic regulation of synaptic transmission from group Ia afferents to motoneurons and interneurons, (2) presynaptic regulation of GABAergic inhibition acting on dorsal root afferents, (3) phasic depolarization of group I afferents, and (4) tonic decrease in the excitability of the afferent fibers (animal data: [24-27]; human data: $[28,29])$. Further, Ib facilitation $[30,31]$ and reciprocal Ia inhibition from flexor nerve afferents onto extensor motoneurons [32] also constitute spinal segmental mechanisms that contribute to the soleus $\mathrm{H}$-reflex amplitude modulation at the stance and swing phases, respectively. Presynaptic inhibition of Ia afferent terminals and Renshaw cells acting on Ia inhibitory interneurons have also been documented [33]. The phase-dependent modulation of soleus and TA MEPs may be attributed to excitability changes of corticomotoneuronal cells [34], corticospinal volleys activating mutual reciprocal inhibitory interneurons $[16,35,36]$, and cortically mediated ongoing changes in presynaptic inhibition of Ia afferents [37]. Excitatory and inhibitory interneurons in the motor cortex may contribute to MEP excitability changes while walking $[38,39]$. The phase-dependent modulation pattern of the short-latency TA flexor reflexes can be partly attributed to amplitude modulation of presynaptic inhibition of cutaneous afferent volleys $[25,40]$.

For a phase-dependent modulation of soleus H-reflex, soleus/TA MEPs, and short-latency TA flexor reflexes to occur, locomotor neuronal networks need to be appropriately engaged at each phase of a step cycle, and thus these networks can depict both the physiological function and the underlying neuronal reorganization of spinal locomotor circuits in spinal-injured humans after repetitive step training.

\section{Plasticity of Neuronal Activity after Locomotor Training}

Following induction of SCI, animal studies have shown that locomotor training improves locomotor capacity beyond spontaneous recovery, full weight-bearing ability is prolonged, and improved locomotion persists up to 6 weeks after training stops [41, 42]. Similarly, in humans with SCI, locomotor training improves limb coordination, limb kinematics, step symmetry, walking speed, endurance, and balance [4349], reduces systolic blood pressure and heart rate [50], improves respiratory function [51], and reduces inflammatory status [52]. Improvements in standing, walking, and respiratory capacity are likely due to plasticity of spinal interneuronal circuits. Below, we discuss evidence surrounding plasticity of neuronal activity after locomotor training in people with SCI.

3.1. Monosynaptic-Polysynaptic Motoneuron Responses While Walking. In people with SCI, the soleus H-reflex modulation pattern while walking varies considerably between patients, from being relatively normal in some to being completely absent in others $[2,53,54]$. The most common abnormal patterns we have observed in people with SCI, regardless of the American Spinal Injury Association Impairment Scale (AIS), are lack of reflex depression during the swing phase 


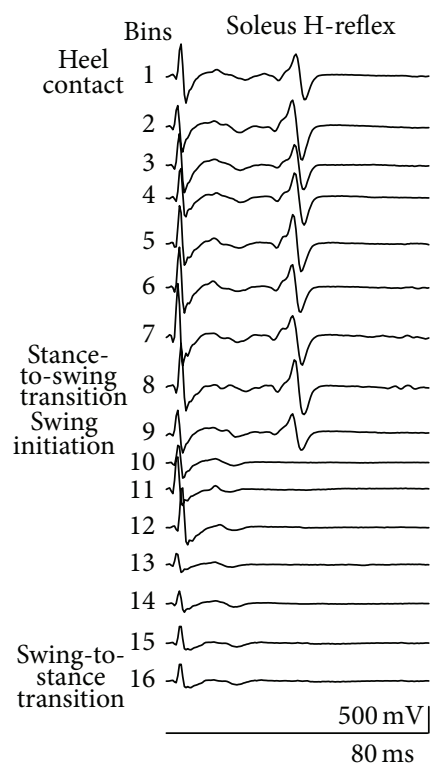

(a)

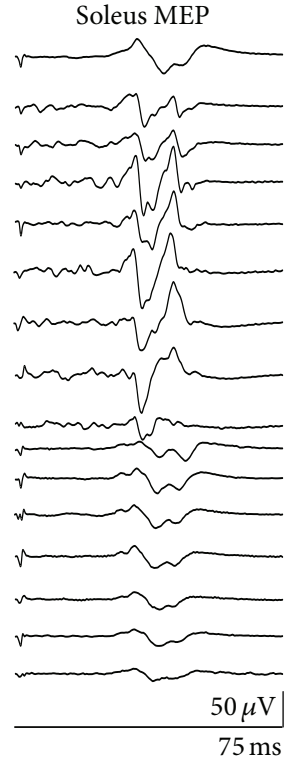

Tibialis anterior MEP

Tibialis anterior flexor reflex Bins

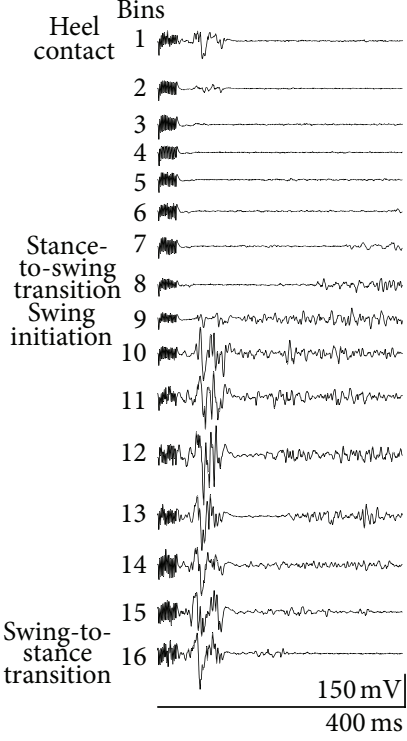

(c)

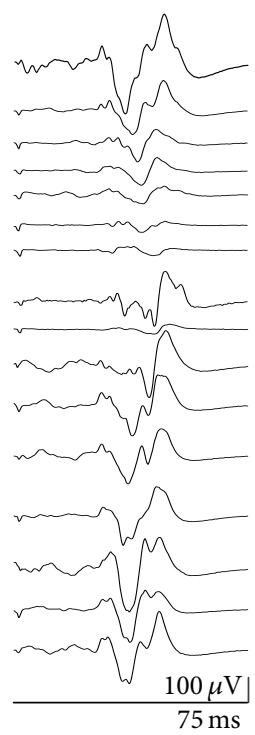

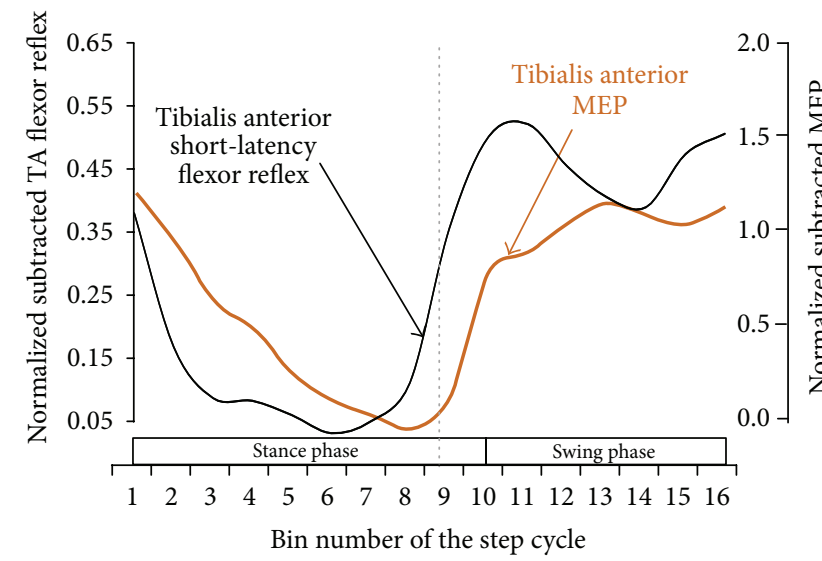

(d)

FIGURE 1: Modulation of neuronal activity while walking in uninjured humans. (a, b) Soleus H-reflexes and soleus motor evoked potentials (MEPs) amplitude at each bin of the step cycle while stepping on a motorized treadmill for single subjects (a) and for a group of healthy subjects (b). (c, d) Short-latency tibialis anterior (TA) flexor reflexes and TA MEPs amplitude at each bin of the step cycle while stepping on a motorized treadmill for single subjects (c) and for a group of healthy subjects (d). For the grouped data, for each bin of the step cycle, the soleus H-reflex was normalized to the maximal M-wave evoked $60-80 \mathrm{~ms}$ after the test H-reflex, and the short-latency TA flexor reflexes and soleus/TA MEPs were normalized to the maximum homonymous locomotor EMG having subtracted the control EMG (EMG without stimulation) at identical time windows and bins. Each step was divided into 16 equal bins based on the signal from the right foot switch. Bin 1 corresponds to heel contact. Bins 8, 9, and 16 correspond approximately to stance-to-swing transition, swing initiation, and swing-to-stance transition, respectively. Vertical dotted lines designate the stance-to-swing transition phase. Data adopted and modified from [2, 16, 21, 22].

and a disruption of sustained reflex excitability during the stance phase [54]. Similarly, the most common change we have observed after locomotor training regardless of the AIS is reestablishment of reflex depression during the swing phase that promotes reciprocal activation of ankle flexors and extensors [54]. Also importantly is our observation that reflex depression at mid-late swing was restored in two cases of motor complete SCI (AIS A-B) (see [54, Figure 2A]). We also observed that this neuronal reorganization was not distributed equally in the more impaired leg compared with 
the less impaired leg, as the soleus H-reflex during the stance phase was moderately decreased across all patients after locomotor training in the more impaired (right) leg compared to the less impaired (left) leg (compare Figures 2 and 3 in [54]).

An additional neuronal characteristic of SCI is the dominance of late long-lasting flexor reflexes over the short-latency flexor reflexes [1,55-57]. While the late long-lasting flexor reflexes in human SCI have a similar interneuronal reorganization to that reported in acute spinal cats treated with LDOPA (reviewed in [58]) and are due largely to the absent mutual inhibitory actions from early onto late flexor reflex interneuronal networks, their relative behavior signifies the altered interneuronal reorganization after injury. We recently reported that locomotor training in people with chronic SCI results in reappearance of short-latency TA flexor reflexes (see [28, Figure 3]), reduces the amplitude of long-latency TA flexor reflexes in the more impaired right leg (see [21, Figure 2]), increases the amplitude of long-latency TA flexor reflexes in the less impaired left leg (see [21, Figure 2]), and promotes a phase-dependent modulation of both short-latency and longlatency TA flexor reflexes during assisted stepping [21].

3.2. Spinal Inhibition. Impaired function of many different spinal inhibitory pathways has been implicated as one of the main causes of pathological movement and muscle tone after SCI, related to reduced GABAergic and glycinergic inhibitory neurotransmission/reception [59]. Physiological measures of neuronal activity, discussed below, strongly support that the main underlying neurophysiological mechanism of locomotor training is the return of the lost spinal inhibition in people with chronic SCI.

3.2.1. Homosynaptic Depression. Homosynaptic (or lowfrequency) depression is a form of presynaptic inhibition (Figure 2(a)) attributed mostly to a decrease in the amount of released neurotransmitters by the previously activated Ia afferents [60-62], depletion of releasable vesicles, failure of action potential conduction at axonal branches [63], decrease of presynaptic quantal size [64], and adaptation of exocytosis machinery [65]. Impaired function or completely absent homosynaptic depression in people with chronic SCI has been linked to stretch reflex hyperexcitability, clonus, and cocontractions due to altered or abnormal synaptic efficacy of afferent impulses [66-68].

Limited evidence exists on the reorganization of homosynaptic depression in animals and humans. Homosynaptic depression was potentiated after passive exercise of complete spinal transected rats [69], after 10 locomotor training sessions in one SCI person capable of ambulation [70] and after cycling in one person with spastic tetraplegia [71]. We recently reported that repetitive locomotor training restores soleus H-reflex homosynaptic depression, but we found significant differences among patient groups [72]. In summary, we found that soleus $\mathrm{H}$-reflex homosynaptic depression was restored in two people with motor complete SCI in both right and left legs, and it became stronger after training in the more impaired right leg compared to the less impaired left leg regardless of the AIS (see [72, Figure 4]). Last, we found that, in cases where some homosynaptic depression was present before training, locomotor training further potentiated the soleus H-reflex homosynaptic depression (see [72, Figure 4]). In Figure 2(b), representative examples of this neuronal organization are indicated from one person with AIS B who received 53 locomotor training sessions. These recordings clearly indicate that the soleus H-reflex amplitude exhibited a strong stimulation frequency-dependent depression after locomotor training even in cases when descending control is greatly impaired or absent [72].

3.2.2. Presynaptic Inhibition. The synaptic efficacy of afferent volleys before they reach their target neurons can be adjusted by presynaptic inhibition (Figure 3(a)). Methods have been developed to probe presynaptic inhibition exerted only at Ia afferent terminals [71]. This is because only Ia afferents have monosynaptic projections to motoneurons and separation from motor fibers based on stimulation intensities and respective thresholds is possible. Presynaptic inhibition was originally described in the cat by Frank and Fuortes [73], is associated with primary afferent depolarization (PAD), is mediated by axoaxonic synapses [74], and involves modulation of transmitter release at the Ia-motoneuron synapse by means of $\mathrm{GABA}_{\mathrm{A}}$ receptors, which consequently increase the efflux of $\mathrm{Cl}^{-}$ions and produce depolarization of the afferent terminals [75].

Presynaptic inhibition is modulated in a phase-dependent manner during fictive and real locomotion in animals, including humans $[25,28,76,77]$, and accounts to a great extent for the differential soleus and quadriceps H-reflex amplitude modulation while walking in uninjured humans $[29,78]$. Functionally, increased presynaptic inhibition of the soleus Ia excitatory feedback may be needed to prevent excessive activation of ankle extensor motoneurons at mid-to-late stance phases (causing a stiff gait), while decreased presynaptic inhibition of the quadriceps Ia excitatory feedback at early stance prepares the knee joint to accept loading. The soleus H-reflex facilitation following femoral nerve stimulation at group I threshold is exerted from quadriceps afferents onto soleus motoneurons via monosynaptic connections, and increases or decreases of this facilitation have been ascribed to changes in the ongoing presynaptic inhibition [79]. The excitatory influence of Ia afferents onto synergistic muscles, as is the case with quadriceps afferents acting onto soleus motoneurons, is also known as heteronymous Ia facilitation. In people with traumatic SCI, the increased heteronymous Ia facilitation supports decreased presynaptic inhibition [80]. The complete disappearance of presynaptic inhibition of Ia afferent terminals of the flexor carpi radialis $\mathrm{H}$-reflex, elicited by electrical stimuli applied to the nerve supplying antagonistic muscles at long conditioning-test intervals, in two patients with tetraplegia due to a spinal cord lesion at C5-C6 [81], supports further abnormal premotoneuronal control after SCI. It has also been shown that the level of presynaptic inhibition declines over time after SCI [66]. The decrease of presynaptic inhibition after SCI is likely related to impaired function of the descending pathways that ensure suppression of inhibitory interneurons transmitting cutaneous inhibition of first-order PAD interneurons [82]. 


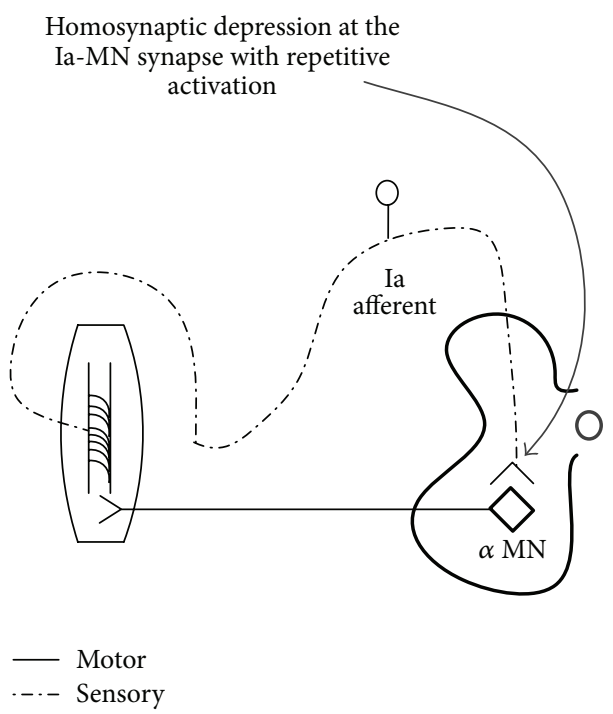

(a)

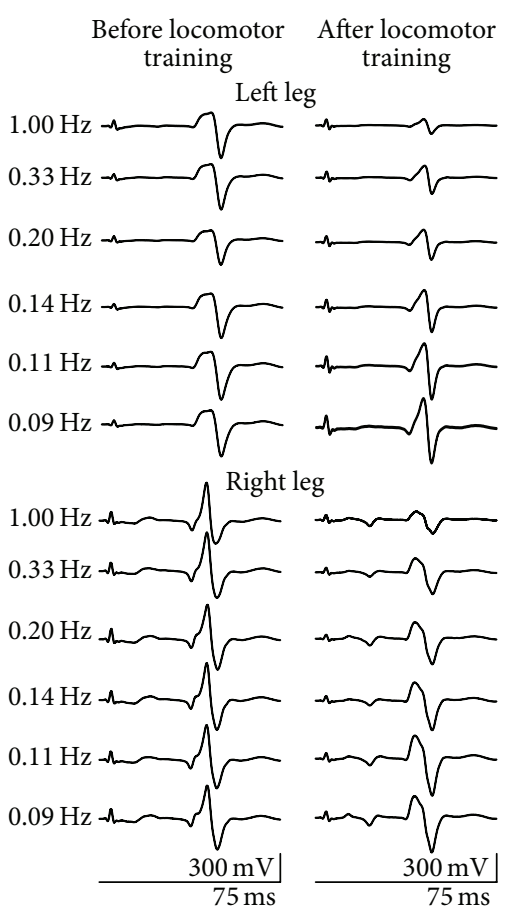

(b)

FIGURE 2: Functional reorganization of homosynaptic depression after locomotor training in SCI. (a) Schematic diagram of the soleus H-reflex homosynaptic depression exerted at Ia-motoneuron synapse with repetitive activation of Ia afferents. (b). Nonrectified waveform averages of soleus H-reflexes recorded at different stimulation frequencies from one AIS B patient before and after locomotor training for both legs. The soleus H-reflex amplitude exhibited a strong stimulation frequency-dependent depression after locomotor training. Data adopted and modified from [72].

We recently reported that presynaptic inhibition of soleus Ia afferents, assessed as the amplitude of the conditioned soleus $\mathrm{H}$-reflex by excitation of antagonistic group I afferents at long conditioning-test intervals in the seated position [15], was reorganized in motor incomplete SCI (AIS C-D) but not in motor complete SCI (AIS A-B) after locomotor training (Figure 3(b)) [72]. We also found that, during assisted stepping, the modulation of presynaptic inhibition occurred at different phases of the step cycle before training when compared to that observed after training [72], and this change was comparable to the modulation pattern we have reported for uninjured human subjects during assisted stepping [77]. Reorganization of presynaptic inhibition can partly account for the return of the physiological soleus $\mathrm{H}$ reflex amplitude modulation while walking after locomotor training found for the same patients [54].

3.2.3. Reciprocal Ia Inhibition. The neuronal pathway from the large muscle spindle (Ia) afferents to antagonistic alpha motoneurons is the most known and well-studied spinal inhibitory pathway in the mammalian CNS (Figure 4(a)), described originally by Lloyd [83-85], with vestibulo-, cortico-, and rubropropriospinal tracts and cutaneous and flexor reflex afferents to affect transmission in the Ia interneurons and their subsequent synaptic inputs onto motoneurons [86]. Ia afferent-mediated reciprocal inhibition is effective in blocking antagonist motoneuron activation at birth in hemisected spinal cord preparations and in humans when rhythmic motor programs have not been developed, used, or stored $[87,88]$. A high specificity of neuronal connections from quadriceps Ia afferents to posterior biceps-semitendinosus motor neurons is reported at birth in mice [89].

The functional significance of reciprocal Ia inhibition is apparent when one considers that this neuronal pathway operates only between flexor and extensors and not between abductors and adductors [91]. Thus, the role of reciprocal Ia inhibition in the alternating activation of flexors and extensors during locomotion might be to eliminate excitatory effects during the passive (swing) phase of the step cycle and remove the enduring Ia excitation during the shifts between flexion and extension phases [92]. Recordings from Ia inhibitory interneurons during fictive locomotion in complete spinally transected cats showed that hyperpolarization of extensor alpha motoneurons during the swing phase is directly related to their activity [93-95], largely determined by intraspinal rhythmic processes [96].

SCI in humans is associated with pathologic changes of reciprocal Ia inhibition, with alterations reported in strength, timing, and modulation at rest, during contraction, and while walking [97-101]. Reciprocal facilitation is related to poor motor recovery of legs, while stronger reciprocal inhibition is linked to less spasticity ( 1 and 2 on the Ashworth score) [102]. 

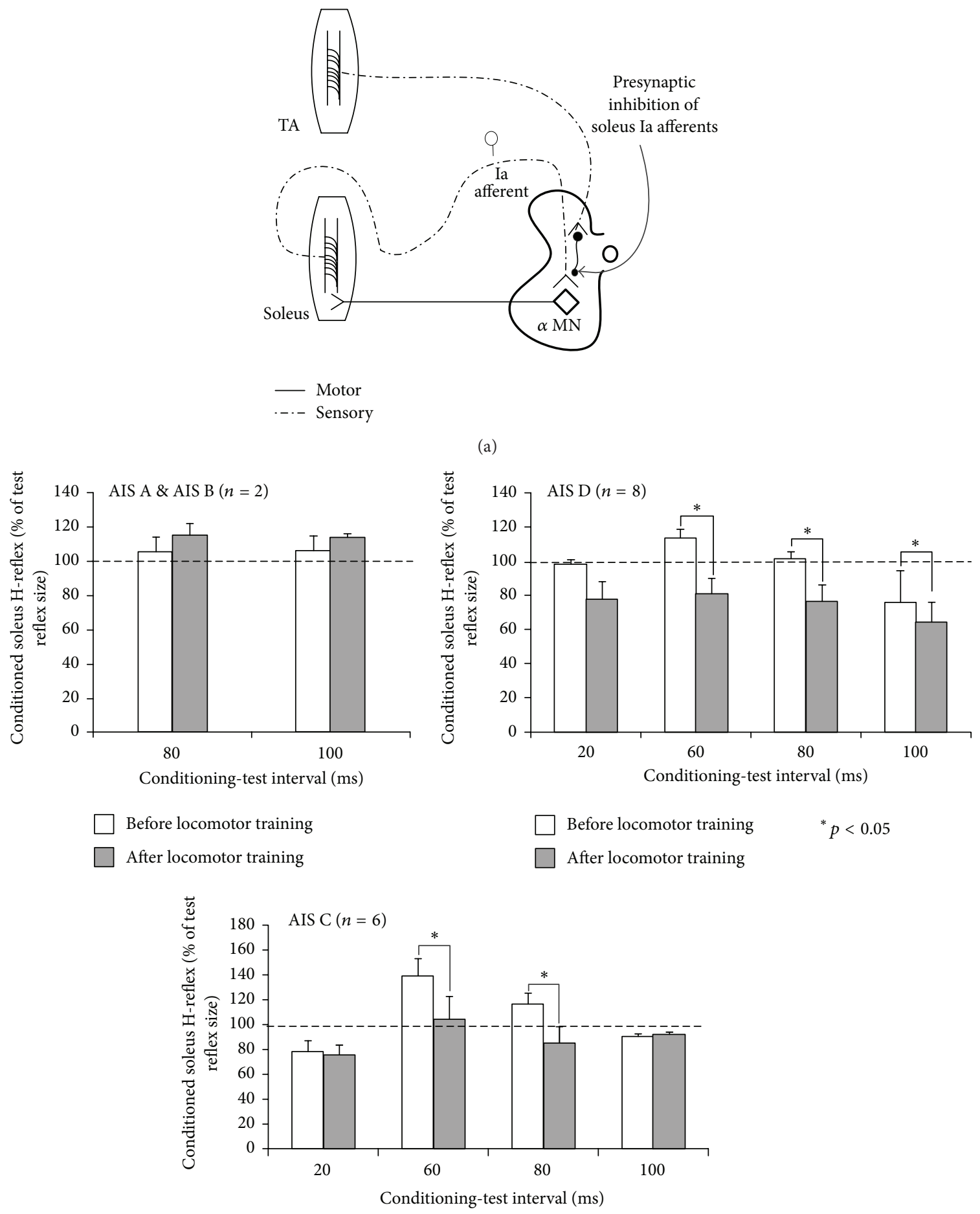

Before locomotor training $\quad{ }^{*} p<0.05$

After locomotor training

(b)

FIGURE 3: Functional reorganization of presynaptic inhibition of soleus Ia afferents after locomotor training in SCI. (a) Schematic diagram of the neuronal pathway of presynaptic inhibition of soleus Ia afferents. In this paradigm, presynaptic inhibition of soleus Ia afferents is induced by a conditioning afferent volley following common peroneal nerve stimulation at long conditioning-test (C-T) intervals. (b) Mean amplitude of the conditioned soleus H-reflex as a percentage of the unconditioned H-reflex recorded at each C-T interval tested before and after locomotor training from the right leg, grouped per AIS, in the seated position. ${ }^{*} p<0.05$ indicate statistically significant differences of the conditioned H-reflexes recorded before and after locomotor training. Data adopted and modified from [72]. 


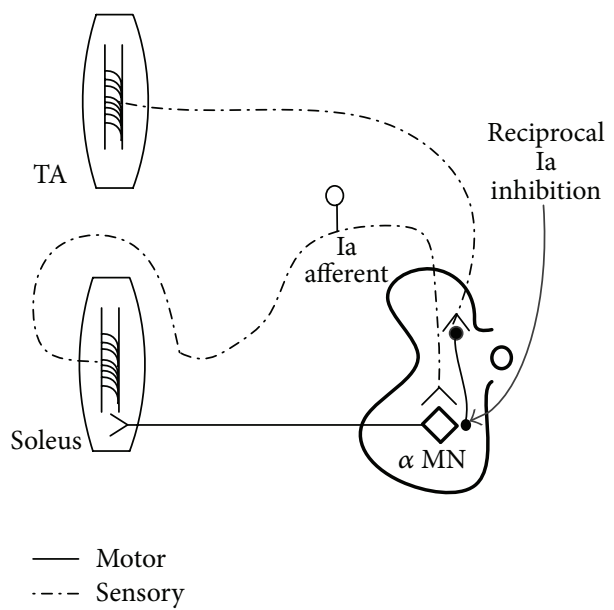

(a)
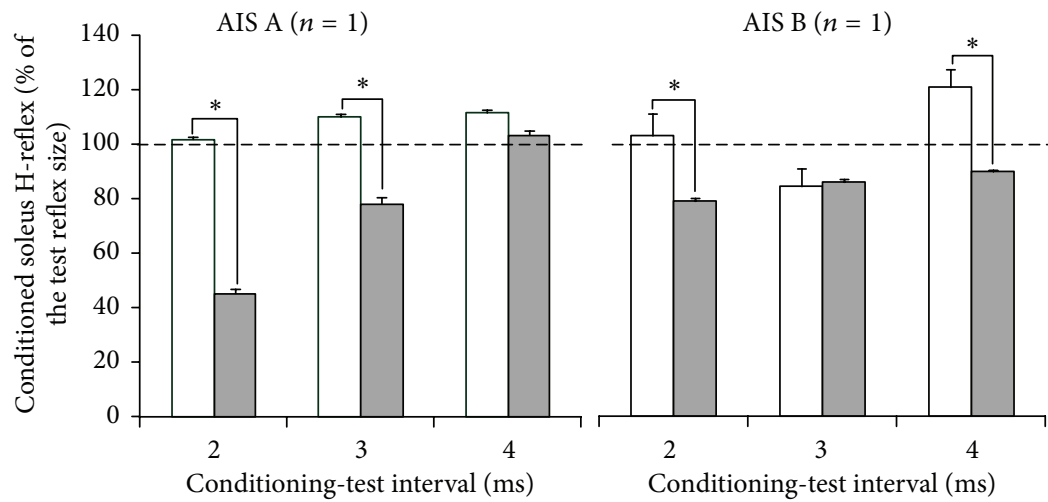

Before locomotor training

${ }^{*} p<0.05$

After locomotor training

$\operatorname{AIS~C~}(n=6)$
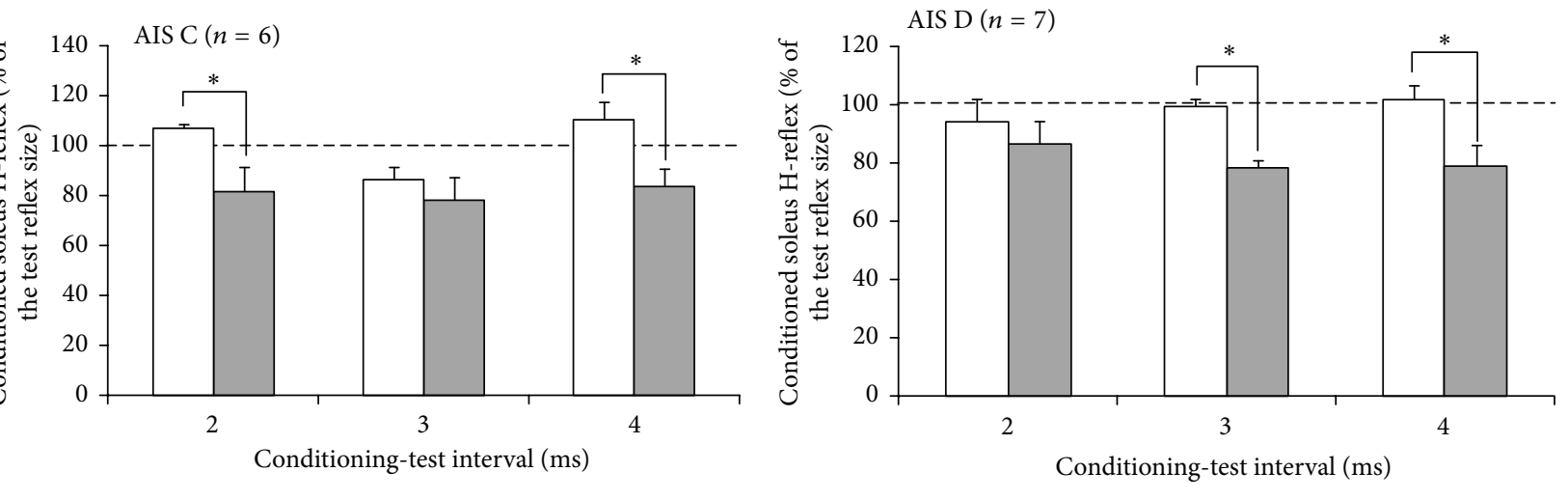

Before locomotor training $\quad{ }^{*} p<0.05$

Before locomotor training $\quad{ }^{*} p<0.05$

After locomotor training

After locomotor training

(b)

FIGURE 4: Functional reorganization of reciprocal Ia inhibition after locomotor training in SCI. (a) Schematic diagram of the neuronal pathway of reciprocal Ia inhibition mediated by a conditioning afferent volley induced by stimulation of the ipsilateral common peroneal nerve at short conditioning-test (C-T) intervals. (b) Mean amplitude of the conditioned soleus H-reflex as a percentage of the unconditioned $\mathrm{H}$-reflex recorded at each C-T interval tested before and after locomotor training from the right leg, grouped per AIS, in the seated position. ${ }^{*} p<0.05$ indicate statistically significant differences of the conditioned $\mathrm{H}$-reflexes recorded before and after locomotor training. Data adopted and modified from [90]. 
In a group of people with SCI, we studied to what extent reciprocal Ia inhibition of soleus motoneurons, assessed as the soleus H-reflex amplitude conditioned by excitation of TA group I afferents at short conditioning-test intervals while seated [15], is restored after locomotor training. We found that reciprocal facilitation was replaced by reciprocal inhibition regardless of the AIS level in the seated position (Figure 4(b)) [90]. However, during assisted stepping the changes were not uniform across AIS patients, because we found that reciprocal Ia inhibition recovered at a greater level in AIS C than in AIS D after locomotor training (see [90, Figure 2]). Reciprocal inhibition was profoundly decreased during the stance phase and increased during the swing phase in AIS C after locomotor training, while, in AIS D, reciprocal inhibition was mostly decreased (see [90, Figure 2]). The reduced amounts of reciprocal inhibition in AIS D can explain the lack of full soleus H-reflex depression during the swing phase we observed in these patients. It is possible that more training sessions or more intense training (i.e., more steps/session) [103] may be required to increase the amount of reciprocal inhibition in some patients with SCI.

3.2.4. Nonreciprocal Ib Inhibition. The views pertaining to the functional role of Ib afferents (Figure 5(a)) have changed substantially from a simple autogenic protective reflex response to the more complicated view that these afferents continuously provide information about the amplitude of muscle contraction. Ib interneurons that mediate such information are widely distributed, reaching almost all motoneuron pools of the ipsilateral limb [104]. Ib interneurons can participate in alternative pathways allowing for excitation or inhibition depending on the selected subpopulation of interneurons [105] and receive extensive convergence from other afferents and descending tracts [106]. It is well established that Ib afferents participate in a reflex reversal during fictive locomotion in decerebrate cats, known as locomotor-related group I excitation, which utilizes a different circuit organization compared to that observed at rest and is transmitted through the extensor half centre [107, 108]. These Ib locomotor excitatory interneurons are located in the intermediate zone in mid to caudal parts of the lower lumbar spinal cord [30]. In summary, group I (mainly Ib) afferents of ankle extensors shape the amplitude, duration, and timing of ipsilateral extensor activity and depending on the timing that excitation occurs they can increase the activity of extensor motoneurons at the stance phase, initiate extension, and terminate or delay flexor bursts in the ipsilateral hind limb [107, 109-112]. A similar facilitatory locomotor group I pathway also exists in humans [113], with Ib inhibition decreasing while loading and reversing to excitation while walking [31].

In people with chronic spinal cord lesions, conflicting evidence exists on this pathway, as nonreciprocal Ib inhibition is reported to be either physiologic or pathologic at rest and during assisted stepping [114-116]. Indeed, we recently reported the presence of short-latency soleus H-reflex depression following medialis gastrocnemius (MG) nerve stimulation at short conditioning-test intervals (attributed mostly to Ib inhibition) in two persons with AIS A and AIS B while seated (Figure 5(b)) [90]. In addition, locomotor training potentiated the preexisting Ib inhibition at rest in AIS A, AIS $\mathrm{B}$, and AIS C (Figure 5(b)), but during assisted stepping we found that the reorganization was different for AIS C and AIS D [90]. In general, changes in Ib inhibition were noted mostly during the swing phase in AIS C patients, while in AIS D patients Ib inhibition was increased at midstance [90]. While these findings are consistent with the reduced shortlatency group I inhibition of synergists at the stance phase of walking in healthy humans and during fictive locomotion in spinal animals $[113,117]$, locomotor training did not induce, as expected, an extra facilitation of soleus motoneuron responses by group Ib afferents during the stance phase. Strengthening Ib polysynaptic excitation with locomotor training during the stance phase of walking may require more training sessions, more steps per session, more body loading, greater allowance for manageable errors, and/or training at different levels of environmental constraints [103, 118].

3.3. Alpha Motoneurons. Altered excitability of spinal neurons is considered a key pathophysiological event after an injury to the spinal cord. The monoamines serotonin and norepinephrine, which are released from pathways originating in the brainstem, substantially modulate spinal motoneuron excitability. Activation of monoamine receptors enhances intrinsic low-voltage-activated persistent inward currents (PICs) that produce plateau potentials and self-sustained firing in both the somata and dendrites, also regulating the gain of the motoneuron pool [119-123]. PICs amplify both synaptic excitation and inhibition, are critical for the dynamic transformation of synaptic inputs, and provide a sustained excitatory drive that allows motoneurons to fire repetitively following a brief synaptic excitation [124-126]. Inhibitory synaptic inputs can exert considerable control over alpha motoneuron discharge by regulating intrinsic PICs activation/deactivation [127].

Despite the lost or reduced brainstem-derived serotonin with chronic SCI, PICs are enhanced due to compensatory upregulation of constitutively active $5-\mathrm{HT}_{2}$ receptors [128]. PICs that drive self-sustained firing in motoneurons have been related to the development of muscle spasms and hyperreflexia to nonnoxious stimuli and clonus [129]. Additionally, the voltage threshold of slow motoneurons changes, axonal conduction velocity, and rheobase current increases, afterhyperpolarization duration decreases [130, 131], short pulse current threshold increases [131], and resting threshold and resting membrane potential decrease [131, 132]. Further, spinal cord transection leads to changes in the rhythmic firing patterns of motoneurons in response to injected currents [132]. In people with SCI, alpha motoneuron PICs and associated self-sustained firing facilitated the firing of motor units during the prolonged muscle spasms that can continue for many seconds, even minutes, at very low discharge rates [133].

Evidence from animal studies suggests that intrinsic properties of motoneurons recover after locomotor training. Motoneurons of trained rats have lower hyperpolarized resting membrane potentials, decreased spike trigger threshold levels (membrane potential at which an action potential is triggered), increased amplitudes of after hyperpolarization (reflecting a decrease in membrane excitability) [134-136], 


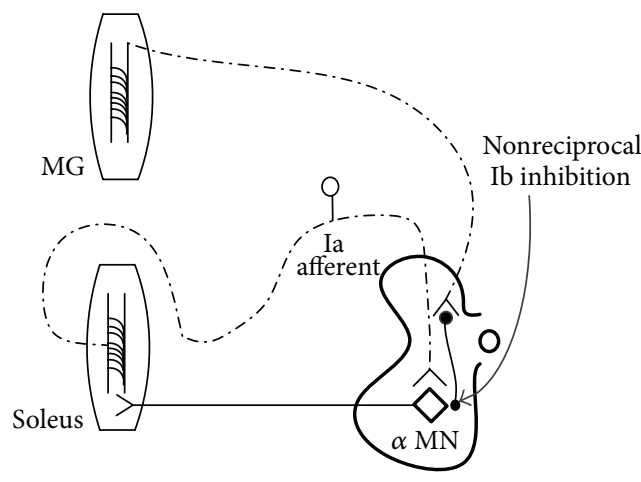

- Motor

-..- Sensory

(a)

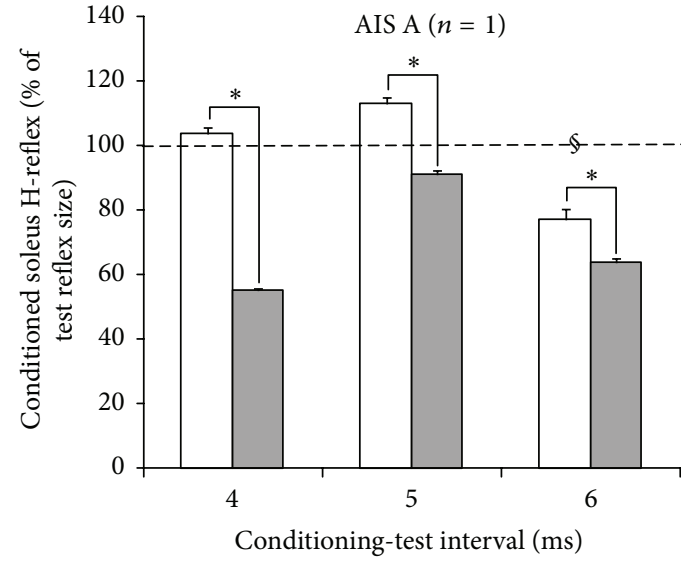

AIS B $(n=1)$

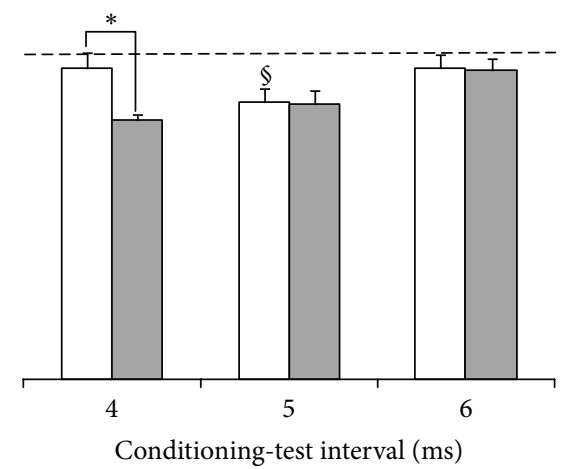

$\begin{array}{ll}{ }^{*} p<0.05 & \$ p<0.05 \\ \text { Before versus after } & \text { Before training: Hcond versus } \\ & \text { Hcontrol }\end{array}$

Before locomotor training

After locomotor training

崩

180 AIS C $(n=5)$

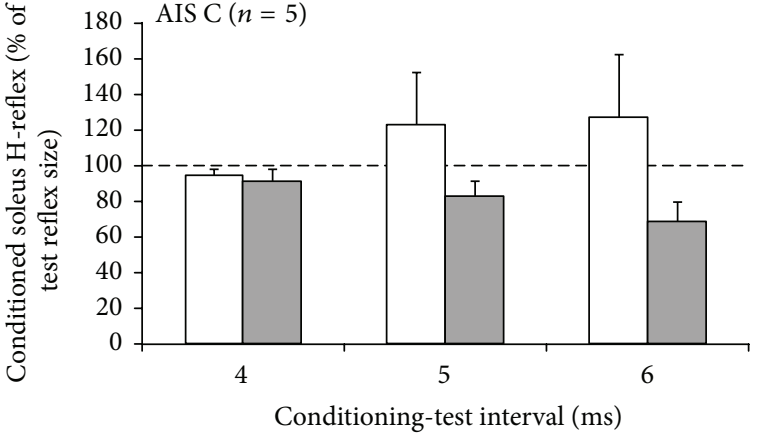

Before locomotor training

After locomotor training

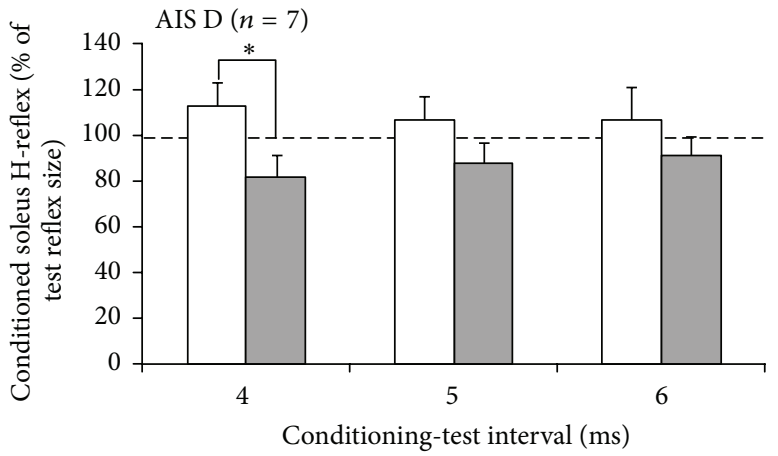

Before locomotor training

${ }^{*} p<0.05$

After locomotor training

Before versus after

(b)

FIGURE 5: Functional reorganization of nonreciprocal Ib inhibition after locomotor training in SCI. (a) Schematic diagram of the neuronal pathway of nonreciprocal Ib inhibition mediated by a conditioning afferent volley induced by stimulation of the ipsilateral medialis gastrocnemius nerve at short conditioning-test (C-T) intervals. The facilitatory locomotor Ib pathway is not indicated. (b) Mean amplitude of the conditioned soleus H-reflex as a percentage of the unconditioned H-reflex recorded at each C-T interval tested before and after locomotor training from the right leg, grouped per AIS, in the seated position. ${ }^{*} p<0.05$ indicate statistically significant differences of the conditioned H-reflexes recorded before and after locomotor training. Data adopted and modified from [90]. 
stabilized dendritic tree structure of motoneurons [137], altered synaptic inputs from the spinal white matter [138], and a soma size and $\mathrm{Na}^{+}, \mathrm{K}^{+}$, and ATPase activity similar to uninjured animals [139]. The duration of training is critical in changing the intrinsic properties of motor neurons, as 3 weeks of training does not restore their electrical properties [140].

Direct changes in the electrical and biophysical properties of motor neurons in SCI patients following locomotor training are difficult to document given the methodological limitations in human studies. However, the amplitude of monosynaptic motoneuron responses at different stimulation intensities along with excitation thresholds can help us draw conclusions on these characteristics. The amplitude and stimulation threshold intensities of the soleus monosynaptic motoneuron responses are not adjusted in untrained SCI patients in the supine and standing positions compared to those observed in uninjured subjects [18]. We found that these parameters were remarkably modified in a body position-dependent manner that depended largely on the leg motor impairment after locomotor training [141]. The maximal H-reflex (Hmax) size was decreased after training while seated and while standing in AIS A and AIS B subjects [141]. The soleus H-reflex size, from the onset of the recruitment curve until its maximum amplitude, was decreased in the right leg in AIS D and in the left leg in AIS C while seated and was increased while standing in both legs in AIS C but not in AIS A, AIS B, and AIS $\mathrm{D}$ [141]. Further, the stimulus corresponding to H-threshold, $50 \%$ Hmax, and Hmax was increased in AIS D, in whom the reflex excitability was decreased in the right leg while seated after training [141, Table 1]. This means that, after locomotor training, more stimulation intensity is required to activate the most excitable Ia afferent fibers that subsequently depolarize the lower threshold (most excitable) soleus motoneurons. The stimulus corresponding to H-reflex threshold expresses the number of active motoneurons or the spinal excitability level, which reflects the balance of excitatory and inhibitory inputs acting on the motoneuron pool [142]. The decreased spinal reflex excitability with the concomitant increased soleus $\mathrm{H}-$ reflex threshold indicates that motoneuron excitability was altered along with the excitability level of Ia afferents.

The increased soleus H-reflex excitability we observed in AIS C subjects while standing after training, compared to that observed before training [141], may enhance ankle stability and thus contribute to an improved leg function while standing. It is known that in uninjured humans, while standing, Ib inhibition exerted from MG to soleus motoneurons is decreased, presynaptic inhibition of soleus Ia afferents is increased, and reciprocal inhibition is decreased when compared to that observed while seated $[31,143,144]$. Thus, both presynaptic inhibition and Ib facilitation after locomotor training may reinforce $\mathrm{H}$-reflex excitability while standing, promoting weight-bearing in people with motor incomplete SCI. The neuronal activity changes we have recently reported after repetitive locomotor training in people with chronic motor complete and incomplete SCI $[21,54,72,90,141]$ are summarized in Table 1 based on body position, motor task, and AIS. These changes can be summarized as follows: (1) monosynaptic motoneuron responses are adjusted in a body position manner, (2) soleus H-reflex phase-dependent modulation is restored, (3) soleus H-reflex homosynaptic depression is restored regardless of AIS, (4) presynaptic inhibition of the soleus Ia afferents evoked by a conditioning stimulus recovers only in AIS C and AIS D, (5) reciprocal Ia inhibition from flexor group I afferents on soleus motoneurons is absent before training and returns regardless of AIS after training, (6) Ib inhibition from MG group I afferents on soleus motoneurons is present before training and is increased after training in AIS A, AIS B, and AIS D, and (7) short-latency flexor reflexes reappear and both shortand long-latency flexor reflexes are modulated in a phasedependent manner [21, 54, 72, 90, 141].

\section{Recovery of Motor Activity after Locomotor Training in SCI}

Motor output can be viewed, without excluding the descending pathways, as the net result of function of motor neurons and interneurons at multisegmental spinal levels. Based on our latest completed locomotor trial in people with SCI and other studies, the changes in motor function can be summarized as (1) increase in peak EMG amplitudes of ankle muscles and decrease in peak EMG amplitudes of medial hamstrings and hip adductor gracilis muscles in the more impaired right leg (medial hamstrings and hip adductor gracilis muscles are known to contribute primarily to the spastic gait pattern and to the pathological leg spasticity pattern at rest) [72, Figure $5 \mathrm{~B}],(2)$ restoration of biphasic EMG activity (when a muscle contracts in more than one phase within a single step cycle) (see [72, Figure 5A]), (3) onset changes of EMG activity while stepping, (4) reduced cocontraction levels between ankle and knee antagonistic muscles (see [72, Figure 5C]), (5) improvements in the alternating activity of the same muscle between the left and right legs, and (6) reduced EMG clonic activity of ankle extensors at rest and on the treadmill [54, $72,145,146]$. However, locomotor training does not restore motor activity similarly in complete and incomplete SCIs. An example of an episode of muscle activity during assisted stepping after locomotor training is shown in Figure 6. The EMG bursts clearly indicate that the ankle antagonistic muscles were activated in a reciprocal pattern after locomotor training in the incomplete SCI subject (AIS D, R014), while a complete absent phase-dependent activity is evident in the complete SCI subject (AIS B, R06) after 53 locomotor training sessions (Figure 6). The lack of distinguished antagonistic EMG bursts with clear onset and offsets in the person with motor complete SCI after locomotor training clearly supports pronounced differences between recovery in animals and humans [147], and thus we need to be cautious when animal data are translated to humans.

The profound changes in motor activity after locomotor training in motor incomplete SCI coincided with changes in gait parameters. The BWS required while stepping was decreased by an average of 55\%, the gait speed was increased by $58 \%$, and the leg guidance force by the robotic exoskeleton was decreased by $43 \%$ [72]. Furthermore, in the motor incomplete subjects, locomotor training improved their lower extremity motor scores, assessed manually by a physical 
TABLE 1: Summary of neuronal activity changes in SCI after locomotor training ${ }^{\#}$.

(a)

\begin{tabular}{|c|c|c|c|c|c|c|}
\hline \multirow{2}{*}{ Neuronal activity } & \multicolumn{2}{|c|}{ AIS A/B } & \multicolumn{2}{|c|}{ AIS C } & \multicolumn{2}{|c|}{ AIS D } \\
\hline & Seated & Stepping & Seated & Stepping & Seated & Stepping \\
\hline $\begin{array}{l}\text { Soleus H-reflex } \\
\text { phase-dependent } \\
\text { modulation }\end{array}$ & NA & $\begin{array}{l}\downarrow \text { stance phase* } \\
\downarrow \text { swing phase* }\end{array}$ & NA & $\downarrow$ swing phase ${ }^{*}$ & NA & $\downarrow$ swing phase ${ }^{*}$ \\
\hline $\begin{array}{l}\text { Homosynaptic } \\
\text { depression }\end{array}$ & Restored ${ }^{*}$ & NA & Restored ${ }^{*}$ & NA & Restored ${ }^{*}$ & NA \\
\hline $\begin{array}{l}\text { Presynaptic inhibition } \\
\text { of Ia afferents }\end{array}$ & No change & Not tested & Restored $^{*}$ & $\begin{array}{l}\downarrow \text { stance phase }{ }^{*} \\
\uparrow \text { swing phase }\end{array}$ & Restored $^{*}$ & $\begin{array}{c}\downarrow \text { late stance } \\
\uparrow \\
\text { swing-to-stance } \\
\text { transition }{ }^{*}\end{array}$ \\
\hline $\begin{array}{l}\text { Reciprocal Ia } \\
\text { inhibition }\end{array}$ & Restored ${ }^{*}$ & Not tested & Restored ${ }^{*}$ & $\begin{array}{l}\downarrow \text { stance phase* } \\
\uparrow \text { swing phase }^{*}\end{array}$ & Restored* & $\begin{array}{l}\downarrow \text { stance phase }{ }^{*} \\
\downarrow \text { swing phase }\end{array}$ \\
\hline $\begin{array}{l}\text { Nonreciprocal Ib } \\
\text { inhibition }\end{array}$ & Restored $^{*}$ & Not tested & No change & $\begin{array}{l}\text { No change in } \\
\quad \text { stance* }^{*} \\
\downarrow \text { early swing* } \\
\uparrow \text { late swing* }\end{array}$ & Restored* & $\downarrow$ stance phase* \\
\hline $\begin{array}{l}\text { Long-latency flexor } \\
\text { reflexes }\end{array}$ & $\begin{array}{l}\downarrow \text { R-Leg* } \\
\uparrow \text { L-Leg }^{*}\end{array}$ & Improved $^{*}$ & $\begin{array}{l}\downarrow \text { R-Leg* } \\
\uparrow \text { L-Leg }^{*}\end{array}$ & Improved $^{*}$ & $\begin{array}{l}\downarrow \text { R-Leg* } \\
\uparrow \text { L-Leg }^{*}\end{array}$ & Improved $^{*}$ \\
\hline $\begin{array}{l}\text { Short-latency flexor } \\
\text { reflexes }\end{array}$ & $\begin{array}{l}\text { Reappeared in } \\
\text { R-Leg* }\end{array}$ & $\begin{array}{c}\text { Phase- } \\
\text { dependent } \\
\text { modulation } \\
\text { emerged in } \\
\text { R-Leg* }\end{array}$ & $\begin{array}{l}\text { Reappeared in } \\
\text { R-Leg* }\end{array}$ & $\begin{array}{l}\text { Phase- } \\
\text { dependent } \\
\text { modulation } \\
\text { emerged in } \\
\text { R-Leg* }\end{array}$ & $\begin{array}{l}\text { Reappeared } \\
\text { in both legs* }\end{array}$ & $\begin{array}{l}\text { Phase- } \\
\text { dependent } \\
\text { modulation } \\
\text { emerged* }\end{array}$ \\
\hline
\end{tabular}

(b)

\begin{tabular}{|c|c|c|c|c|c|c|}
\hline \multirow{2}{*}{ Neuronal activity } & \multicolumn{2}{|c|}{ AIS A/B } & \multicolumn{2}{|c|}{ AIS C } & \multicolumn{2}{|c|}{ AIS D } \\
\hline & Seated & Standing & Seated & Standing & Seated & Standing \\
\hline $\begin{array}{l}\text { Soleus motoneuron } \\
\text { excitability (Hmax) }\end{array}$ & $\begin{array}{l}\text { No change in } \\
\text { R/L-Legs }\end{array}$ & $\begin{array}{l}\text { No change in } \\
\text { R/L-Legs }\end{array}$ & $\begin{array}{c}\text { No change in } \\
\text { R-Leg* } \\
\downarrow \text { L-Leg* }\end{array}$ & $\uparrow \mathrm{R} /$ L-Legs* & $\begin{array}{c}\downarrow \text { R-Leg* } \\
\text { No change in } \\
\text { L-Leg* }\end{array}$ & $\begin{array}{l}\text { No change in } \\
\text { R/L-Legs }\end{array}$ \\
\hline H-threshold & $\begin{array}{l}\text { No change in } \\
\text { R/L-Legs }\end{array}$ & $\begin{array}{l}\text { No change in } \\
\text { R/L-Legs }\end{array}$ & $\begin{array}{l}\text { No change in } \\
\text { R/L-Legs }\end{array}$ & $\begin{array}{c}\text { No change in } \\
\text { R/L-Legs }\end{array}$ & $\begin{array}{c}\uparrow \text { R-Leg* } \\
\text { No change in } \\
\text { L-Leg* }\end{array}$ & $\begin{array}{c}\downarrow \text { L-Leg* }^{*} \\
\text { No change in } \\
\text { R-Leg* }\end{array}$ \\
\hline
\end{tabular}

$\bar{~}{ }^{\#}$ Neuronal activity changes after locomotor training in people with SCI are from authors' recent published work [21, 54, 72, 90, 141]. R: right; L: left; and NA: not applicable; symbols $\uparrow / \downarrow$ indicate increased or decreased neuronal activity. $*$ refers to neuronal activity changes.

therapist, with the more impaired right leg improving by $10 \%$ and the left leg improving by $6.4 \%$ [21], a motor improvement also reported for cervical and thoracic AIS D patients [148].

\section{Pathways and Circuits Underlying Neuronal and Motor Plasticity after Locomotor Training}

The CNS adapts and reorganizes continuously based on motor experience and use. This natural reorganization is the result of physiological, anatomical, and functional neuronal changes along the neuroaxis (cortex, cerebellum, spinal cord, and nerve axons) [149]. After an injury to the spinal cord, neuronal reorganization occurs that eventually results in neural circuits/pathways with altered properties and functions. The findings on the neuronal activity changes in animals and in humans detailed in the above paragraphs support that locomotor trainingcan promote functional neuronalreorganization [150]. A major drive to the neuronal reorganization after locomotor training is reinforcement of activity-dependent sensory feedback from receptors (including but not limited to plantar mechanoreceptors and hip proprioceptors) that can adjust the operation of the CPG $[11,151,152]$.

Sources for neuronal activity changes in people with SCI after locomotor training could include modifications in the intrinsic properties and function of the somata and dendrites of neurons, excitability profile of motoneuron pools, excitability thresholds of muscle afferents, modulation of EPSPs from afferents, and modifications on the descending control of spinal reflex networks involving synaptic and nonsynaptic mechanisms. These changes most likely occur simultaneously at differing strengths during the course of locomotor training, while adjustments made to the BWS, treadmill speed, and 

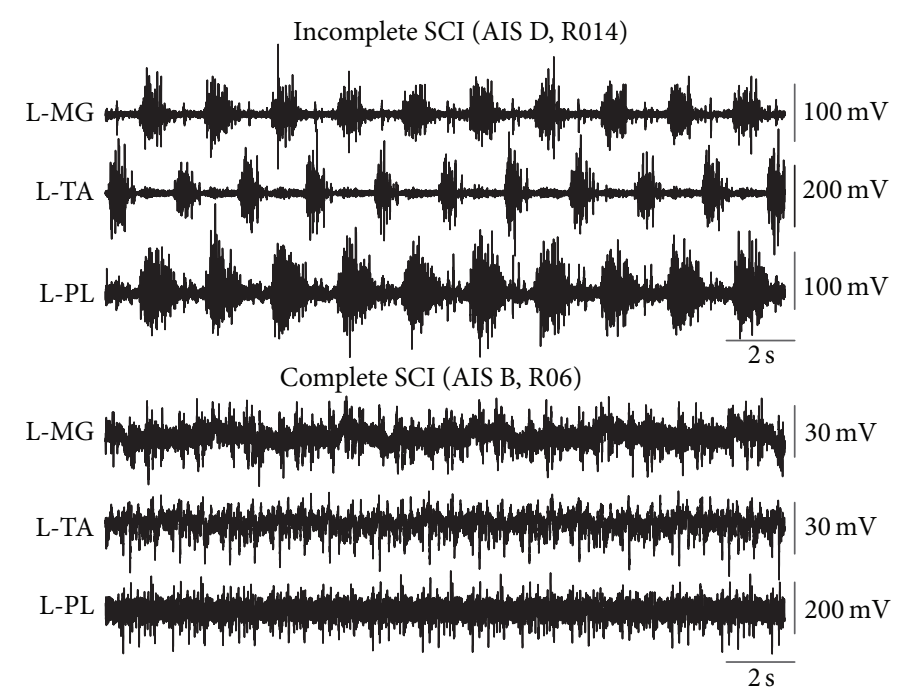

FIGURE 6: Motor activity after locomotor training in incomplete and complete SCI. Nonrectified electromyographic (EMG) activity from 10 consecutive steps of medialis gastrocnemius (MG), tibialis anterior (TA), and peroneus longus (PL) muscles from the left legs in one motor incomplete SCI subject (AIS D) and in one motor complete SCI subject (AIS B) during assisted stepping after locomotor training. Note in subject R014 that MG and PL occur in a reciprocal pattern with the TA, but distinctive EMG bursts are absent in subject R06.

leg guidance force during the course of training [54] affected the reorganization of spinal neuronal pathways integrating information about body loading and muscle stretch.

The restored soleus H-reflex depression during the swing phase in motor complete SCI we observed after locomotor training points towards three directions: (1) the soleus $\mathrm{H}$ reflex depression during the swing phase cannot be attributed solely to reciprocal Ia inhibition between ankle antagonistic muscles because the physiological supraspinal control of Ia inhibitory interneurons (animal: [98, 153, 154]; human: [98, $155]$ ) is greatly impaired in AIS A and AIS B, (2) reciprocal Ia inhibition can become functional after locomotor training even when descending control is impaired, and (3) functional behavior of reciprocal Ia inhibition is not depicted well in the EMG bursts during assisted stepping (see EMG bursts of AIS B subject in Figure 6). While all of these directions entail limitations with respect to the relevant contribution of reciprocal inhibition to the reflex depression during the swing phase of gait, it is possible that this change represents the capacity of intrinsic properties of the spinal cord to alter rhythmic motor activity after training [156].

Differences between right-left leg soleus H-reflex modulation changes suggest that the connections made by commissural spinal cord interneurons to motoneurons $[156,157]$ might have been affected differently by locomotor training in some patients compared to others. Commissural interneurons interact with 5-HT and GABA systems, form excitatory and inhibitory connections onto contralateral motoneurons at latencies consistent with monosynaptic and polysynaptic pathways, are under descending influence, and support locomotor rhythm generation in response to brainstem stimulation [157-163]. Further, midline lesions and photoablation affecting the axons of these neurons eliminate rhythmic ventral root bursting, alter the symmetry of ventral root bursts, and can eliminate rhythmic bursting [163], supporting the contribution of commissural interneurons to rhythmogenesis.

In healthy humans, ipsilateral posterior tibial nerve stimulation or knee extension joint rotation produces inhibition in both the contralateral soleus motoneurons and the reflex responses in the contralateral biceps femoris muscle, both being modulated according to the phase of walking [164167]. Crossed postsynaptic inhibition in contralateral soleus motoneurons from ipsilateral groups I and II afferents at short latencies (3-7 ms), similar to those reported for the feline spinal cord, has recently been described for humans [168]. Further, activation of contralateral hip proprioceptors results in ipsilateral soleus H-reflex depression [169]. Taken altogether, differences between right-left leg $\mathrm{H}$-reflex changes during the stance phase may thus represent plastic changes of commissural interneurons, but it is evident that there is a need for in-depth exploration of the physiological changes of commissural interneurons in people with SCI after locomotor training.

Changes in presynaptic and postsynaptic inhibition after locomotor training may be related to changes in the strength of the depolarization of muscle afferents $[24,170,171]$ or may be the result of transformations in the intrinsic properties of spinal neurons and afferents after locomotor training. For example, in anesthetized chronic spinal cats there is an overall increase in Ia excitatory postsynaptic potentials (EPSPs) in ankle extensor motoneurons [172]. Plantar mechanoreceptors interact with presynaptic inhibitory interneurons, in humans at rest and in spinalized cats during fictive locomotion [54, 173]. Additionally, plantar mechanoreceptors evoke a phasedependent modulation of primary afferent depolarization $[24,25]$, alter their effects on spinal motoneurons in spinalized cats after step training [173], and normalize the function of monosynaptic spinal reflexes while stepping in untrained spinal cord-injured patients [174]. Changes in the intrinsic 
properties of spinal neurons after locomotor training are supported by the increased density of the glycinergic axonal terminals and decreased size of both glycinergic and GABAergic axon terminals in complete spinal trained transected rats compared to nontrained transected rats [175]. Because plasticity of the glycinergic system, which mediates inhibitory neurotransmission, occurs independently of supraspinal influence [176] and reciprocal Ia inhibition was potentiated after training in complete SCI at rest but recovery while stepping varied between patients, direct descending inputs on Ia inhibitory interneurons may not be a key source for neuroplasticity. However, this may be required for long-term support of inhibitory synaptic transmission and regulation of the depth of reciprocal Ia inhibition during locomotion.

The aforementioned are possible physiological changes in complete SCI, but the neuronal reorganization is more complex in incomplete SCI because neuronal structures above the lesion site might adapt the function and behavior of spinal neuronal circuitries known to control locomotor activity through remnant descending pathways. In incomplete SCIs, the plasticity of uninjured fibers plays an important role in functional recovery. In cats and monkeys, as little as $25 \%$ of remaining white matter tracts can allow for recovery of voluntary locomotor ability $[177,178]$, and a similar observation was found in humans following partial spinal cord transection to provide cancer pain relief [179]. Animal studies provide substantial direct evidence that, following a hemisection injury to the corticospinal tract, transected fibers sprout into cervical gray matter to communicate with propriospinal interneurons, whose propriospinal neurons then relay the motor command to distal lumbosacral motoneurons [180185]. In rats, this corticopropriospinal connection can be enhanced pharmacologically [186] and with locomotor treadmill training [187]. Considerable indirect evidence suggests that this pathway is preserved in humans [188-192] and may be probed utilizing TMS and peripheral nerve stimulation $[192,193]$. Future research on this pathway in humans with SCI and the effects of locomotor training is warranted.

\section{Functional Consequences of Neuronal and Motor Plasticity}

A question that arises is as follows: to what extent is plasticity of neuronal activity related to improvement of motor function in SCI patients? Although improvements in gait parameters were noted over the course of training, overground walking ability assessed by the 6-min walk test, and the number of sit-to-stand repetitions completed within $30 \mathrm{~s}$, and the time needed to rise from a chair, walk for $3 \mathrm{~m}$, and return to the chair were not improved after locomotor training in AIS C and AIS D [54]. Lack of changes in these walking ability variables could be related to (1) number of training sessions per participant, (2) small number of participants, (3) existence of nonresponders within the group, and (4) the fact that the 6min walk test may not be sensitive enough to detect improvements in quality of walking of patients with SCI [194]. It may be also the case that the benefits seen with robotic-assisted treadmill training did not carry over into the task-specific overground testing of the 6 min walk test. However, previous literature involving locomotor training with as-needed manual assistance or with robotic-driven leg assistance in motor incomplete SCI demonstrated improvements in the walking index for SCI version II (WISCI-II) scale, overground walking speed, Berg balance scores, and 6 min walk test $[146,195-$ 198]. Further, locomotor training improves lower extremity motor scores in both motor complete and motor incomplete SCIs [199, 200]. Taken altogether and including gaps in the literature, it is apparent that the time course of neuronal plasticity with corresponding motor recovery needs to be established.

\section{Concluding Remarks}

Locomotor training of persons with clinically complete, motor complete, or motor incomplete SCI induces reorganization of spinal neuronal networks that coincides with improvements in motor activity and decreased pathophysiological phenomena of the spasticity syndrome. However, to maximize recovery of motor function in patients with SCI, we need to utilize both established (i.e., locomotor training, spinal cord stimulation) and contemporary (i.e., brain controlled intraspinal microstimulation) technologies/interventions simultaneously and change the focus of our research questions from "feasibility" and "efficacy" to "what are the physiological mechanisms that make it work?" and "for which category of patients?" Additionally, while we need to better understand the physiological changes underlying locomotor training, especially of the uninjured fibers, research efforts should concentrate on providing strong scientific evidence when more than one intervention is utilized concomitantly. Over the course of treatment, physiological signals can be used to (1) probe recovery, (2) develop algorithms that may be used to define the approach of locomotor training for each patient, and (3) predict functional recovery. These approaches will enable the scientific and clinical community to develop more effective rehabilitation protocols.
Abbreviations
AIS:
American Spinal Injury Association
BWS:
CNS:
CPGs: Impairment Scale
C-T interval: Conditioning-test interval
EMG: Electromyograms/electromyography
EPSPs: Excitatory postsynaptic potentials
Hmax: $\quad$ Maximal H-reflex
MG: $\quad$ Medialis gastrocnemius
MEP: $\quad$ Motor evoked potential
PAD: $\quad$ Primary afferent depolarization
SCI: $\quad$ Spinal cord injury
TA: Tibialis anterior
TMS: $\quad$ Transcranial magnetic stimulation.

\section{Disclosure}

This review does not represent the views of the NIH, Craig Neilsen Foundation, or NYSDOH. 


\section{Competing Interests}

No conflict of interests, financial or otherwise, is declared by the authors.

\section{Acknowledgments}

Andrew C. Smith is supported by the Foundation for Physical Therapy Promotion of Doctoral Studies Programs and the NIH Extramural Loan Repayment Program for Clinical Research. Maria Knikou is supported by The Craig H. Neilsen (CHN) Foundation (339705) and by the New York State Department of Health (NYSDOH) (DOH01-C30836GG3450000), Spinal Cord Injury Program, Wadsworth Center.

\section{References}

[1] M. Knikou, "Plantar cutaneous input modulates differently spinal reflexes in subjects with intact and injured spinal cord," Spinal Cord, vol. 45, no. 1, pp. 69-77, 2007.

[2] M. Knikou, C. A. Angeli, C. K. Ferreira, and S. J. Harkema, "Soleus H-reflex modulation during body weight support treadmill walking in spinal cord intact and injured subjects," Experimental Brain Research, vol. 193, no. 3, pp. 397-407, 2009.

[3] V. L. Arvanian, L. Schnell, L. Lou et al., "Chronic spinal hemisection in rats induces a progressive decline in transmission in uninjured fibers to motoneurons," Experimental Neurology, vol. 216, no. 2, pp. 471-480, 2009.

[4] D. Barthélemy, M. Willerslev-Olsen, H. Lundell et al., "Impaired transmission in the corticospinal tract and gait disability in spinal cord injured persons," Journal of Neurophysiology, vol. 104, no. 2, pp. 1167-1176, 2010.

[5] K. E. Tansey, W. B. McKay, and B. A. Kakulas, "Restorative neurology: consideration of the new anatomy and physiology of the injured nervous system," Clinical Neurology and Neurosurgery, vol. 114, no. 5, pp. 436-440, 2012.

[6] T. Brown, "The intrinsic factors in the act of progression in the mammal," Procceedings of the Royal Society Biology, vol. 84, no. 572, pp. 308-319, 1911.

[7] C. S. Sherrington, "Flexion-reflex of the limb, crossed extension-reflex, and reflex stepping and standing," The Journal of Physiology, vol. 40, no. 1-2, pp. 28-121, 1910.

[8] C. S. Sherrington, "Further observations on the production of reflex stepping by combination of reflex excitation with reflex inhibition," The Journal of Physiology, vol. 47, no. 3, pp. 196-214, 1913.

[9] I. A. Rybak, K. J. Dougherty, and N. A. Shevtsova, "Organization of the mammalian locomotor CPG: review of computational model and circuit architectures based on genetically identified spinal interneurons," eNeuro, vol. 2, no. 5, 2015.

[10] N. A. Shevtsova, A. E. Talpalar, S. N. Markin, R. M. HarrisWarrick, O. Kiehn, and I. A. Rybak, "Organization of left-right coordination of neuronal activity in the mammalian spinal cord: insights from computational modelling," The Journal of Physiology, vol. 593, no. 11, pp. 2403-2426, 2015.

[11] S. Rossignol, "Plasticity of connections underlying locomotor recovery after central and/or peripheral lesions in the adult mammals," Philosophical Transactions of the Royal Society B: Biological Sciences, vol. 361, no. 1473, pp. 1647-1671, 2006.

[12] H. Barbeau, M. Wainberg, and L. Finch, "Description and application of a system for locomotor rehabilitation," Medical and Biological Engineering and Computing, vol. 25, no. 3, pp. 341-344, 1987.

[13] V. Dietz, "Body weight supported gait training: from laboratory to clinical setting," Brain Research Bulletin, vol. 78, no. 1, pp. 1-6, 2009.

[14] G. Colombo, M. Wirz, and V. Dietz, "Driven gait orthosis for improvement of locomotor training in paraplegic patients," Spinal Cord, vol. 39, no. 5, pp. 252-255, 2001.

[15] M. Knikou, "The H-reflex as a probe: pathways and pitfalls," Journal of Neuroscience Methods, vol. 171, no. 1, pp. 1-12, 2008.

[16] M. Knikou, N. Hajela, and C. K. Mummidisetty, "Corticospinal excitability during walking in humans with absent and partial body weight support," Clinical Neurophysiology, vol. 124, no. 12, pp. 2431-2438, 2013.

[17] J. Duysens, A. A. M. Tax, M. Trippel, and V. Dietz, "Phasedependent reversal of reflexly induced movements during human gait," Experimental Brain Research, vol. 90, no. 2, pp. 404-414, 1992.

[18] M. Knikou, C. A. Angeli, C. K. Ferreira, and S. J. Harkema, "Soleus H-reflex gain, threshold, and amplitude as function of body posture and load in spinal cord intact and injured subjects," International Journal of Neuroscience, vol. 119, no. 11, pp. 2056-2073, 2009.

[19] E. B. Simonsen, "Contributions to the understanding of gait control," Danish Medical Journal, vol. 61, no. 4, Article ID B4823, 2014.

[20] M. Schubert, A. Curt, L. Jensen, and V. Dietz, "Corticospinal input in human gait: modulation of magnetically evoked motor responses," Experimental Brain Research, vol. 115, no. 2, pp. 234246, 1997.

[21] A. C. Smith, C. K. Mummidisetty, W. Z. Rymer, and M. Knikou, "Locomotor training alters the behavior of flexor reflexes during walking in human spinal cord injury," Journal of Neurophysiology, vol. 112, no. 9, pp. 2164-2175, 2014.

[22] M. Knikou, N. Hajela, C. K. Mummidisetty, M. Xiao, and A. C. Smith, "Soleus H-reflex phase-dependent modulation is preserved during stepping within a robotic exoskeleton," Clinical Neurophysiology, vol. 122, no. 7, pp. 1396-1404, 2011.

[23] J. F. Yang and P. J. Whelan, "Neural mechanisms that contribute to cyclical modulation of the soleus H-reflex in walking in humans," Experimental Brain Research, vol. 95, no. 3, pp. 547$556,1993$.

[24] J.-P. Gossard, "Control of transmission in muscle group IA afferents during fictive locomotion in the cat," Journal of Neurophysiology, vol. 76, no. 6, pp. 4104-4112, 1996.

[25] A. Ménard, H. Leblond, and J.-P. Gossard, "Sensory integration in presynaptic inhibitory pathways during fictive locomotion in the cat," Journal of Neurophysiology, vol. 88, no. 1, pp. 163-171, 2002.

[26] S. Gosgnach, J. Quevedo, B. Fedirchuk, and D. A. McCrea, "Depression of group Ia monosynaptic EPSPs in cat hindlimb motoneurones during fictive locomotion," The Journal of Physiology, vol. 526, no. 3, pp. 639-652, 2000.

[27] S. H. Dueñas and P. Rudomin, "Excitability changes of ankle extensor group Ia and Ib fibers during fictive locomotion in the cat," Experimental Brain Research, vol. 70, no. 1, pp. 15-25, 1988.

[28] C. Morin, R. Katz, L. Mazieres, and E. Pierrot-Deseilligny, "Comparison of soleus $\mathrm{H}$ reflex facilitation at the onset of soleus contractions produced voluntarily and during the stance phase of human gait," Neuroscience Letters, vol. 33, no. 1, pp. 47-53, 1982. 
[29] M. Faist, V. Dietz, and E. Pierrot-Deseilligny, "Modulation, probably presynaptic in origin, of monosynaptic Ia excitation during human gait," Experimental Brain Research, vol. 109, no. 3, pp. 441-449, 1996.

[30] M. J. Angel, E. Jankowska, and D. A. McCrea, "Candidate interneurones mediating group I disynaptic EPSPs in extensor motoneurones during fictive locomotion in the cat," The Journal of Physiology, vol. 563, no. 2, pp. 597-610, 2005.

[31] M. Faist, C. Hoefer, M. Hodapp, V. Dietz, W. Berger, and J. Duysens, "In humans Ib facilitation depends on locomotion while suppression of Ib inhibition requires loading," Brain Research, vol. 1076, no. 1, pp. 87-92, 2006.

[32] C. Ethier, M.-A. Imbeault, V. Ung, and C. Capaday, "On the soleus H-reflex modulation pattern during walking," Experimental Brain Research, vol. 151, no. 3, pp. 420-425, 2003.

[33] M. Enríquez-Denton, J. Nielsen, M.-C. Perreault, H. Morita, N. Petersen, and H. Hultborn, "Presynaptic control of transmission along the pathway mediating disynaptic reciprocal inhibition in the cat," The Journal of Physiology, vol. 526, no. 3, pp. 623-637, 2000.

[34] N. Petersen, L. O. D. Christensen, and J. Nielsen, "The effect of transcranial magnetic stimulation on the soleus $\mathrm{H}$ reflex during human walking," The Journal of Physiology, vol. 513, no. 2, pp. 599-610, 1998.

[35] L. Kudina, P. Ashby, and L. Downes, "Effects of cortical stimulation on reciprocal inhibition in humans," Experimental Brain Research, vol. 94, no. 3, pp. 533-538, 1993.

[36] B. Hanna-Boutros, S. Sangari, L.-S. Giboin et al., "Corticospinal and reciprocal inhibition actions on human soleus motoneuron activity during standing and walking," Physiological Reports, vol. 3, no. 2, Article ID e12276, 2015.

[37] S. Meunier and E. Pierrot-Deseilligny, "Cortical control of presynaptic inhibition of Ia afferents in humans," Experimental Brain Research, vol. 119, no. 4, pp. 415-426, 1998.

[38] U.Ziemann, S. Lönnecker, B. J. Steinhoff, and W. Paulus, "Effects of antiepileptic drugs on motor cortex excitability in humans: a transcranial magnetic stimulation study," Annals of Neurology, vol. 40, no. 3, pp. 367-378, 1996.

[39] T. Ito, A. Tsubahara, K. Shinkoda, Y. Yoshimura, K. Kobara, and H. Osaka, "Excitability changes in intracortical neural circuits induced by differentially controlled walking patterns," PLoS ONE, vol. 10, no. 2, Article ID e0117931, 2015.

[40] J. C. Eccles, P. G. Kostyuk, and R. F. Schmidt, "Presynaptic inhibition of the central actions of flexor reflex afferents," The Journal of Physiology, vol. 161, pp. 258-281, 1962.

[41] R. G. Lovely, R. J. Gregor, R. R. Roy, and V. R. Edgerton, "Effects of training on the recovery of full-weight-bearing stepping in the adult spinal cat," Experimental Neurology, vol. 92, no. 2, pp. 421-435, 1986.

[42] R. D. de Leon, H. Tamaki, J. A. Hodgson, R. R. Roy, and V. R. Edgerton, "Hindlimb locomotor and postural training modulates glycinergic inhibition in the spinal cord of the adult spinal cat," Journal of Neurophysiology, vol. 82, no. 1, pp. 359369, 1999.

[43] V. Dietz, G. Colombo, and L. Jensen, "Locomotor activity in spinal man," The Lancet, vol. 344, no. 8932, pp. 1260-1263, 1994.

[44] V. Dietz, M. Wirz, A. Curt, and G. Colombo, "Locomotor pattern in paraplegic patients: training effects and recovery of spinal cord function," Spinal Cord, vol. 36, no. 6, pp. 380-390, 1998.
[45] A. Wernig, S. Muller, A. Nanassy, and E. Cagol, "Laufband therapy based on 'rules of spinal locomotion' is effective in spinal cord injured persons," European Journal of Neuroscience, vol. 7, no. 4, pp. 823-829, 1995.

[46] E. C. Field-Fote, S. D. Lindley, and A. L. Sherman, "Locomotor training approaches for individuals with spinal cord injury: a preliminary report of walking-related outcomes," Journal of Neurologic Physical Therapy, vol. 29, no. 3, pp. 127-137, 2005.

[47] B. Dobkin, D. Apple, H. Barbeau et al., "Weight-supported treadmill vs over-ground training for walking after acute incomplete SCI," Neurology, vol. 66, no. 4, pp. 484-493, 2006.

[48] M. Wu, J. M. Landry, B. D. Schmit, T. G. Hornby, and S.-C. Yen, "Robotic resistance treadmill training improves locomotor function in human spinal cord injury: a pilot study," Archives of Physical Medicine and Rehabilitation, vol. 93, no. 5, pp. 782-789, 2012.

[49] S. J. Harkema, M. Schmidt-Read, D. J. Lorenz, V. R. Edgerton, and A. L. Behrman, "Balance and ambulation improvements in individuals with chronic incomplete spinal cord injury using locomotor training-based rehabilitation," Archives of Physical Medicine and Rehabilitation, vol. 93, no. 9, pp. 1508-1517, 2012.

[50] D. S. Ditor, M. V. Kamath, M. J. MacDonald, J. Bugaresti, N. McCartney, and A. L. Hicks, "Effects of body weight-supported treadmill training on heart rate variability and blood pressure variability in individuals with spinal cord injury," Journal of Applied Physiology, vol. 98, no. 4, pp. 1519-1525, 2005.

[51] D. Terson de Paleville, W. McKay, S. Aslan, R. Folz, D. Sayenko, and A. Ovechkin, "Locomotor step training with body weight support improves respiratory motor function in individuals with chronic spinal cord injury," Respiratory Physiology and Neurobiology, vol. 189, no. 3, pp. 491-497, 2013.

[52] M. Turiel, S. Sitia, S. Cicala et al., "Robotic treadmill training improves cardiovascular function in spinal cord injury patients," International Journal of Cardiology, vol. 149, no. 3, pp. 323-329, 2011.

[53] J. F. Yang, J. Fung, M. Edamura, R. Blunt, R. B. Stein, and H. Barbeau, "H-reflex modulation during walking in spastic paretic subjects," Canadian Journal of Neurological Sciences, vol. 18, no. 4, pp. 443-452, 1991.

[54] M. Knikou, "Functional reorganization of soleus H-reflex modulation during stepping after robotic-assisted step training in people with complete and incomplete spinal cord injury," Experimental Brain Research, vol. 228, no. 3, pp. 279-296, 2013.

[55] A. Roby-Brami and B. Bussel, "Long-latency spinal reflex in man after flexor reflex afferent stimulation," Brain, vol. 110, no. 3, pp. 707-725, 1987.

[56] M. Knikou and B. A. Conway, "Effects of electrically induced muscle contraction on flexion reflex in human spinal cord injury," Spinal Cord, vol. 43, no. 11, pp. 640-648, 2005.

[57] B. A. Conway and M. Knikou, "The action of plantar pressure on flexion reflex pathways in the isolated human spinal cord," Clinical Neurophysiology, vol. 119, no. 4, pp. 892-896, 2008.

[58] M. Knikou, "Neural control of locomotion and traininginduced plasticity after spinal and cerebral lesions," Clinical Neurophysiology, vol. 121, no. 10, pp. 1655-1668, 2010.

[59] S. Shapiro, "Neurotransmission by neurons that use serotonin, noradrenaline, glutamate, glycine, and $\gamma$-aminobutyric acid in the normal and injured spinal cord," Neurosurgery, vol. 40, no. 1, pp. 168-177, 1997.

[60] M. Kuno, "Quantal components of excitatory synaptic potentials in spinal motoneurones," The Journal of Physiology, vol. 175, no. 1, pp. 81-99, 1964. 
[61] H. Hultborn, M. Illert, J. Nielsen, A. Paul, M. Ballegaard, and H. Wiese, "On the mechanism of the post-activation depression of the H-reflex in human subjects," Experimental Brain Research, vol. 108, no. 3, pp. 450-462, 1996.

[62] A. F. Kohn, M. K. Floeter, and M. Hallett, "Presynaptic inhibition compared with homosynaptic depression as an explanation for soleus H-reflex depression in humans," Experimental Brain Research, vol. 116, no. 2, pp. 375-380, 1997.

[63] D. L. Brody and D. T. Yue, "Release-independent short-term synaptic depression in cultured hippocampal neurons," Journal of Neuroscience, vol. 20, no. 7, pp. 2480-2494, 2000.

[64] G. Chen, N. C. Harata, and R. W. Tsien, "Paired-pulse depression of unitary quantal amplitude at single hippocampal synapses," Proceedings of the National Academy of Sciences of the United States of America, vol. 101, no. 4, pp. 1063-1068, 2004.

[65] S.-F. Hsu, G. J. Augustine, and M. B. Jackson, "Adaptation of $\mathrm{Ca}^{2+}$-triggered exocytosis in presynaptic terminals," Neuron, vol. 17, no. 3, pp. 501-512, 1996.

[66] B. Calancie, J. G. Broton, K. J. Klose, M. Traad, J. Difini, and D. Ram Ayyar, "Evidence that alterations in presynaptic inhibition contribute to segmental hypo- and hyperexcitability after spinal cord injury in man," Electroencephalography and Clinical Neurophysiology, vol. 89, no. 3, pp. 177-186, 1993.

[67] E. C. Field-Fote, K. M. Brown, and S. D. Lindley, "Influence of posture and stimulus parameters on post-activation depression of the soleus $\mathrm{H}$-reflex in individuals with chronic spinal cord injury," Neuroscience Letters, vol. 410, no. 1, pp. 37-41, 2006.

[68] M. J. Grey, K. Klinge, C. Crone et al., "Post-activation depression of Soleus stretch reflexes in healthy and spastic humans," Experimental Brain Research, vol. 185, no. 2, pp. 189-197, 2008.

[69] N. B. Reese, R. D. Skinner, D. Mitchell et al., "Restoration of frequency-dependent depression of the $\mathrm{H}$-reflex by passive exercise in spinal rats," Spinal Cord, vol. 44, no. 1, pp. 28-34, 2006.

[70] M. H. Trimble, C. G. Kukulka, and A. L. Behrman, "The effect of treadmill gait training on low-frequency depression of the soleus H-reflex: comparison of a spinal cord injured man to normal subjects," Neuroscience Letters, vol. 246, no. 3, pp. 186$188,1998$.

[71] T. S. Kiser, N. B. Reese, T. Maresh et al., "Use of a motorized bicycle exercise trainer to normalize frequency-dependent habituation of the H-reflex in spinal cord injury," Journal of Spinal Cord Medicine, vol. 28, no. 3, pp. 241-245, 2005.

[72] M. Knikou and C. K. Mummidisetty, "Locomotor training improves premotoneuronal control after chronic spinal cord injury," Journal of Neurophysiology, vol. 111, no. 11, pp. 22642275, 2014.

[73] K. Frank and M. Fuortes, "Presynaptic and postsynaptic inhibition of monosynaptic reflexes," Federal Proceedings, vol. 16, pp. 39-40, 1957.

[74] J. C. Eccles, "Presynaptice inhibition in the spinal cord," Progress in Brain Research, vol. 12, pp. 65-91, 1964.

[75] P. Rudomin and R. F. Schmidt, "Presynaptic inhibition in the vertebrate spinal cord revisited," Experimental Brain Research, vol. 129, no. 1, pp. 1-37, 1999.

[76] M.-P. Côté, A. Ménard, and J.-P. Gossard, "Spinal cats on the treadmill: changes in load pathways," The Journal of Neuroscience, vol. 23, no. 7, pp. 2789-2796, 2003.

[77] C. K. Mummidisetty, A. C. Smith, and M. Knikou, "Modulation of reciprocal and presynaptic inhibition during robotic-assisted stepping in humans," Clinical Neurophysiology, vol. 124, no. 3, pp. 557-564, 2013.
[78] V. Dietz, M. Faist, and E. Pierrot-Deseilligny, "Amplitude modulation of the quadriceps H-reflex in the human during the early stance phase of gait," Experimental Brain Research, vol. 79, no. 1, pp. 221-224, 1990.

[79] H. Hultborn, S. Meunier, C. Morin, and E. Pierrot-Deseilligny, "Assessing changes in presynaptic inhibition of Ia fibres: a study in man and the cat," The Journal of Physiology, vol. 389, pp. 729756, 1987.

[80] M. Faist, D. Mazevet, V. Dietz, and E. Pierrot-Deseilligny, "A quantitative assessment of presynaptic inhibition of Ia afferents in spastics. Differences in hemiplegics and paraplegics," Brain, vol. 117, pp. 1449-1455, 1994.

[81] C. Aymard, R. Katz, C. Lafitte et al., "Presynaptic inhibition and homosynaptic depression: a comparison between lower and upper limbs in normal human subjects and patients with hemiplegia," Brain, vol. 123, no. 8, pp. 1688-1702, 2000.

[82] E. Pierrot-Deseilligny and D. Burke, Spinal and Corticospinal Mechanisms of Movement, Cambridge University Press, New York, NY, USA, 2012.

[83] D. P. C. Lloyd, "Neuron patterns controlling transmission of ipsilateral hind limb reflexes in cat," Journal of Neurophysiology, vol. 6, no. 4, pp. 293-315, 1943.

[84] D. Lloyd, "Facilitation and inhibition of spinal motoneurones," Journal of Neurophysiology, vol. 9, pp. 317-326, 1946.

[85] D. Lloyd, "A direct central inhibitory action of dromically conducted impulses," Journal of Neurophysiology, vol. 4, pp. 184190, 1941.

[86] H. Hultborn, "Convergence on interneurones in the reciprocal Ia inhibitory pathway to motoneurones," Acta Physiologica Scandinavica, vol. 85, pp. 1-42, 1972.

[87] P. M. Sonner and D. R. Ladle, "Early postnatal development of GABAergic presynaptic inhibition of Ia proprioceptive afferent connections in mouse spinal cord," Journal of Neurophysiology, vol. 109, no. 8, pp. 2118-2128, 2013.

[88] S. M. Mc Donough, G. J. Clowry, S. Miller, and J. A. Eyre, "Reciprocal and Renshaw (recurrent) inhibition are functional in man at birth," Brain Research, vol. 899, no. 1-2, pp. 66-81, 2001.

[89] Z. Wang, L. Li, M. Goulding, and E. Frank, "Early postnatal development of reciprocal Ia inhibition in the murine spinal cord," Journal of Neurophysiology, vol. 100, no. 1, pp. 185-196, 2008.

[90] M. Knikou, A. C. Smith, and C. K. Mummidisetty, "Locomotor training improves reciprocal and nonreciprocal inhibitory control of soleus motoneurons in human spinal cord injury," Journal of Neurophysiology, vol. 113, no. 7, pp. 2447-2460, 2015.

[91] R. M. Eccles and A. Lundberg, "Supraspinal control of interneurones mediating spinal reflexes," Journal of Physiology, vol. 147, no. 3, pp. 565-584, 1959.

[92] S. Lindström, "Recurrent control from motor axon collaterals of Ia inhibitory pathways in the spinal cord of the cat," Acta Physiologica Scandinavica Supplement, vol. 392, pp. 1-43, 1973.

[93] C. A. Pratt and L. M. Jordan, "Ia inhibitory interneurons and Renshaw cells as contributors to the spinal mechanisms of fictive locomotion," Journal of Neurophysiology, vol. 57, no. 1, pp. 56-71, 1987.

[94] A. M. Degtyarenko, E. S. Simon, and R. E. Burke, "Differential modulation of disynaptic cutaneous inhibition and excitation in ankle flexor motoneurons during fictive locomotion," Journal of Neurophysiology, vol. 76, no. 5, pp. 2972-2985, 1996. 
[95] S. S. Geertsen, K. Stecina, C. F. Meehan, J. B. Nielsen, and H. Hultborn, "Reciprocal Ia inhibition contributes to motoneuronal hyperpolarisation during the inactive phase of locomotion and scratching in the cat," The Journal of Physiology, vol. 589, no. 1, pp. 119-134, 2011.

[96] A. G. Feldman and G. N. Orlovsky, "Activity of interneurons mediating reciprocal la inhibition during locomotion," Brain Research, vol. 84, no. 2, pp. 181-194, 1975.

[97] C. Crone, J. Nielsen, N. Petersen, M. Ballegaard, and H. Hultborn, "Disynaptic reciprocal inhibition of ankle extensors in spastic patients," Brain, vol. 117, no. 5, pp. 1161-1168, 1994.

[98] C. Crone and J. Nielsen, "Central control of disynaptic reciprocal inhibition in humans," Acta Physiologica Scandinavica, vol. 152, no. 4, pp. 351-363, 1994.

[99] G. I. Boorman, R. G. Lee, W. J. Becker, and U. R. Windhorst, "Impaired 'natural reciprocal inhibition' in patients with spasticity due to incomplete spinal cord injury," Electroencephalography and Clinical Neurophysiology, vol. 101, no. 2, pp. 84-92, 1996.

[100] H. Morita, C. Crone, D. Christenhuis, N. T. Petersen, and J. B. Nielsen, "Modulation of presynaptic inhibition and disynaptic reciprocal Ia inhibition during voluntary movement in spasticity," Brain, vol. 124, no. 4, pp. 826-837, 2001.

[101] M. Knikou and C. K. Mummidisetty, "Reduced reciprocal inhibition during assisted stepping in human spinal cord injury," Experimental Neurology, vol. 231, no. 1, pp. 104-112, 2011.

[102] Y. Okuma, Y. Mizuno, and R. G. Lee, "Reciprocal Ia inhibition in patients with asymmetric spinal spasticity," Clinical Neurophysiology, vol. 113, no. 2, pp. 292-297, 2002.

[103] R. D. de Leon, P. A. See, and C. H. T. Chow, "Differential effects of low versus high amounts of weight supported treadmill training in spinally transected rats," Journal of Neurotrauma, vol. 28, no. 6, pp. 1021-1033, 2011.

[104] J. C. Eccles, R. M. Eccles, and A. Lundberg, "Synaptic actions on motoneurones caused by impulses in Golgi tendon organ afferents," The Journal of Physiology, vol. 138, no. 2, pp. 227-252, 1957.

[105] E. Jankowska, "Interneuronal relay in spinal pathways from proprioceptors," Progress in Neurobiology, vol. 38, no. 4, pp. 335378, 1992.

[106] E. Jankowska and A. Lundberg, "Interneurones in the spinal cord," Trends in Neurosciences, vol. 4, pp. 230-233, 1981.

[107] J.-P. Gossard, R. M. Brownstone, I. Barajon, and H. Hultborn, "Transmission in a locomotor-related group Ib pathway from hindlimb extensor muscles in the cat," Experimental Brain Research, vol. 98, no. 2, pp. 213-228, 1994.

[108] J. Quevedo, B. Fedirchuk, S. Gosgnach, and D. A. McCrea, "Group I disynaptic excitation of cat hindlimb flexor and bifunctional motoneurones during fictive locomotion," The Journal of Physiology, vol. 525, no. 2, pp. 549-564, 2000.

[109] J. Duysens and K. G. Pearson, "Inhibition of flexor burst generation by loading ankle extensor muscles in walking cats," Brain Research, vol. 187, no. 2, pp. 321-332, 1980.

[110] B. A. Conway, H. Hultborn, and O. Kiehn, "Proprioceptive input resets central locomotor rhythm in the spinal cat," Experimental Brain Research, vol. 68, no. 3, pp. 643-656, 1987.

[111] P. Guertin, M. J. Angel, M.-C. Perreault, and D. A. McCrea, "Ankle extensor group I afferents excite extensors throughout the hindlimb during fictive locomotion in the cat," Journal of Physiology, vol. 487, no. 1, pp. 197-209, 1995.
[112] P. J. Whelan, G. W. Hiebert, and K. G. Pearson, "Stimulation of the group I extensor afferents prolongs the stance phase in walking cats," Experimental Brain Research, vol. 103, no. 1, pp. 20-30, 1995.

[113] M. Stephens and J. Yang, "Short latency, non-reciprocal group I inhibition is reduced during the stance phase of walking in humans," Brain Research, vol. 743, no. 1-2, pp. 24-31, 1996.

[114] L. Downes, P. Ashby, and J Bugaresti, "Reflex effects from Golgi tendon organ (Ib) afferents are unchanged after spinal cord lesions in humans," Neurology, vol. 45, no. 9, pp. 1720-1724, 1995.

[115] H. Morita, M. Shindo, H. Momoi, S. Yanagawa, S. Ikeda, and N. Yanagisawa, "Lack of modulation of Ib inhibition during antagonist contraction in spasticity," Neurology, vol. 67, no. 1, pp. 52-56, 2006.

[116] M. Knikou, "Function of group IB inhibition during assisted stepping in human spinal cord injury," Journal of Clinical Neurophysiology, vol. 29, no. 3, pp. 271-277, 2012.

[117] D. A. McCrea, S. J. Shefchyk, M. J. Stephens, and K. G. Pearson, "Disynaptic group I excitation of synergist ankle extensor motoneurones during fictive locomotion in the cat," The Journal of Physiology, vol. 487, no. 2, pp. 527-539, 1995.

[118] V. Dietz, "Proprioception and locomotor disorders," Nature Reviews Neuroscience, vol. 3, no. 10, pp. 781-790, 2002.

[119] P. J. Harvey, X. Li, Y. Li, and D. J. Bennett, "Endogenous monoamine receptor activation is essential for enabling persistent sodium currents and repetitive firing in rat spinal motoneurons," Journal of Neurophysiology, vol. 96, no. 3, pp. 1171-1186, 2006.

[120] P. J. Harvey, X. Li, Y. Li, and D. J. Bennett, “5-HT2 receptor activation facilitates a persistent sodium current and repetitive firing in spinal motoneurons of rats with and without chronic spinal cord injury," Journal of Neurophysiology, vol. 96, no. 3, pp. 1158-1170, 2006.

[121] J. Hounsgaard, H. Hultborn, B. Jespersen, and O. Kiehn, "Bistability of $\alpha$-motoneurones in the decerebrate cat and in the acute spinal cat after intravenous 5-hydroxytryptophan," The Journal of Physiology, vol. 405, pp. 345-367, 1988.

[122] X. Li, K. Murray, P. J. Harvey, E. W. Ballou, and D. J. Bennett, "Serotonin facilitates a persistent calcium current in motoneurons of rats with and without chronic spinal cord injury," Journal of Neurophysiology, vol. 97, no. 2, pp. 1236-1246, 2007.

[123] C. J. Heckman, M. A. Gorassini, and D. J. Bennett, "Persistent inward currents in motoneuron dendrites: implications for motor output," Muscle and Nerve, vol. 31, no. 2, pp. 135-156, 2005.

[124] H. Hultborn, M. E. Denton, J. Wienecke, and J. B. Nielsen, "Variable amplification of synaptic input to cat spinal motoneurones by dendritic persistent inward current," The Journal of Physiology, vol. 552, no. 3, pp. 945-952, 2003.

[125] R. H. Lee and C. J. Heckman, "Adjustable amplification of synaptic input in the dendrites of spinal motoneurons in vivo," The Journal of Neuroscience, vol. 20, no. 17, pp. 6734-6740, 2000.

[126] J. F. Prather, R. K. Powers, and T. C. Cope, "Amplification and linear summation of synaptic effects on motoneuron firing rate," Journal of Neurophysiology, vol. 85, no. 1, pp. 43-53, 2001.

[127] T. V. Bui, G. Grande, and P. K. Rose, "Multiple modes of amplification of synaptic inhibition to motoneurons by persistent inward currents," Journal of Neurophysiology, vol. 99, no. 2, pp. 571-582, 2008.

[128] K. C. Murray, A. Nakae, M. J. Stephens et al., "Recovery of motoneuron and locomotor function after spinal cord injury 
depends on constitutive activity in 5-HT2C receptors," Nature Medicine, vol. 16, no. 6, pp. 694-700, 2010.

[129] D. J. Bennett, Y. Li, P. J. Harvey, and M. Gorassini, "Evidence for plateau potentials in tail motoneurons of awake chronic spinal rats with spasticity," Journal of Neurophysiology, vol. 86, no. 4, pp. 1972-1982, 2001.

[130] T. C. Cope, S. C. Bodine, M. Fournier, and V. R. Edgerton, "Soleus motor units in chronic spinal transected cats: physiological and morphological alterations," Journal of Neurophysiology, vol. 55, no. 6, pp. 1202-1220, 1986.

[131] S. Hochman and D. A. McCrea, "Effects of chronic spinalization on ankle extensor motoneurons. II. Motoneuron electrical properties," Journal of Neurophysiology, vol. 71, no. 4, pp. 14681479, 1994.

[132] E. Beaumont, J. D. Houlé, C. A. Peterson, and P. F. Gardiner, "Passive exercise and fetal spinal cord transplant both help to restore motoneuronal properties after spinal cord transection in rats," Muscle and Nerve, vol. 29, no. 2, pp. 234-242, 2004.

[133] M. A. Gorassini, M. E. Knash, P. J. Harvey, D. J. Bennett, and J. F. Yang, "Role of motoneurons in the generation of muscle spasms after spinal cord injury," Brain, vol. 127, no. 10, pp. 2247-2258, 2004.

[134] E. Beaumont and P. Gardiner, "Effects of daily spontaneous running on the electro-physiological properties of hindlimb motoneurones in rats," The Journal of Physiology, vol. 540, no. 1, pp. 129-138, 2002.

[135] E. Beaumont and P. F. Gardiner, "Endurance training alters the biophysical properties of hindlimb motoneurons in rats," Muscle and Nerve, vol. 27, no. 2, pp. 228-236, 2003.

[136] E. Beaumont, S. Kaloustian, G. Rousseau, and B. Cormery, "Training improves the electrophysiological properties of lumbar neurons and locomotion after thoracic spinal cord injury in rats," Neuroscience Research, vol. 62, no. 3, pp. 147-154, 2008.

[137] V.-R. Gazula, M. Roberts, C. Luzzio, A. F. Jawad, and R. G. Kalb, "Effects of limb exercise after spinal cord injury on motor neuron dendrite stucture," Journal of Comparative Neurology, vol. 476, no. 2, pp. 130-145, 2004.

[138] J. C. Petruska, R. M. Ichiyama, E. D. Crown et al., "Changes in motoneuron properties and synaptic inputs related to step training after spinal cord transection in rats," The Journal of Neuroscience, vol. 27, no. 16, pp. 4460-4471, 2007.

[139] J. Ilha, L. A. Centenaro, N. Broetto Cunha et al., "The beneficial effects of treadmill step training on activity-dependent synaptic and cellular plasticity markers after complete spinal cord injury," Neurochemical Research, vol. 36, no. 6, pp. 1046-1055, 2011.

[140] J. R. Flynn, L. R. Dunn, M. P. Galea, R. Callister, R. J. Callister, and M. M. Rank, "Exercise training after spinal cord injury selectively alters synaptic properties in neurons in adult mouse spinal cord," Journal of Neurotrauma, vol. 30, no. 10, pp. 891-896, 2013.

[141] A. C. Smith, W. Z. Rymer, and M. Knikou, "Locomotor training modifies soleus monosynaptic motoneuron responses in human spinal cord injury," Experimental Brain Research, vol. 233, no. 1, pp. 89-103, 2015.

[142] C. Capaday and R. B. Stein, "Difference in the amplitude of the human soleus $\mathrm{H}$ reflex during walking and running," The Journal of Physiology, vol. 392, pp. 513-522, 1987.

[143] R. Kratz, S. Meunier, and E. Pierrot-Deseilligny, "Changes in presynaptic inhibition of Ia fibres in man while standing," Brain, vol. 111, no. 2, pp. 417-437, 1988.
[144] J. Nielson and Y. Kagamihara, "The regulation of disynaptic reciprocal Ia inhibition during co-contraction of antagonistic muscles in man," The Journal of Physiology, vol. 456, pp. 373391, 1992.

[145] M. A. Gorassini, J. A. Norton, J. Nevett-Duchcherer, F. D. Roy, and J. F. Yang, "Changes in locomotor muscle activity after treadmill training in subjects with incomplete spinal cord injury," Journal of Neurophysiology, vol. 101, no. 2, pp. 969-979, 2009.

[146] J. C. Shin, J. Y. Kim, H. K. Park, and N. Y. Kim, "Effect of roboticassisted gait training in patients with incomplete spinal cord injury," Annals of Rehabilitation Medicine, vol. 38, no. 6, pp. 719725, 2014.

[147] H. Barbeau and S. Rossignol, "Recovery of locomotion after chronic spinalization in the adult cat," Brain Research, vol. 412, no. 1, pp. 84-95, 1987.

[148] B. Dobkin, H. Barbeau, D. Deforge et al., "The evolution of walking-related outcomes over the first 12 weeks of rehabilitation for incomplete traumatic spinal cord injury: the multicenter randomized Spinal Cord Injury Locomotor Trial," Neurorehabilitation and Neural Repair, vol. 21, no. 1, pp. 25-35, 2007.

[149] S. A. Dunlop, "Activity-dependent plasticity: implications for recovery after spinal cord injury," Trends in Neurosciences, vol. 31, no. 8, pp. 410-418, 2008.

[150] O. Raineteau and M. E. Schwab, "Plasticity of motor systems after incomplete spinal cord injury," Nature Reviews Neuroscience, vol. 2, no. 4, pp. 263-273, 2001.

[151] S. Rossignol, G. Barrière, A. Frigon et al., "Plasticity of locomotor sensorimotor interactions after peripheral and/or spinal lesions," Brain Research Reviews, vol. 57, no. 1, pp. 228-240, 2008.

[152] S. N. Markin, A. N. Klishko, N. A. Shevtsova, M. A. Lemay, B. I. Prilutsky, and I. A. Rybak, "Afferent control of locomotor CPG: insights from a simple neuromechanical model," Annals of the New York Academy of Sciences, vol. 1198, pp. 21-34, 2010.

[153] E. Jankowska, Y. Padel, and R. Tanaka, "Disynaptic inhibition of spinal motoneurones from the motor cortex in the monkey," The Journal of Physiology, vol. 258, no. 2, pp. 467-487, 1976.

[154] A. Lundberg, "Multisensory control of spinal reflex pathways," in Reflex Control of Posture and Movement, R. Granit and O. Pomeiano, Eds., pp. 11-28, Elsevier, Amsterdam, The Netherlands, 1979.

[155] E. Fournier, R. Karz, and E. Pierrot-Deseilligny, "Descending control of reflex pathways in the production of voluntary isolated movements in man," Brain Research, vol. 288, no. 1-2, pp. 375-377, 1983.

[156] A. Birinyi, K. Viszokay, I. Wéber, O. Kiehn, and M. Antal, "Synaptic targets of commissural interneurons in the lumbar spinal cord of neonatal rats," Journal of Comparative Neurology, vol. 461, no. 4, pp. 429-440, 2003.

[157] S. J. B. Butt, J. M. Lebret, and O. Kiehn, "Organization of left-right coordination in the mammalian locomotor network," Brain Research Reviews, vol. 40, no. 1-3, pp. 107-117, 2002.

[158] S. J. B. Butt and O. Kiehn, "Functional identification of interneurons responsible for left-right coordination of hindlimbs in mammals," Neuron, vol. 38, no. 6, pp. 953-963, 2003.

[159] S. A. Edgley, E. Jankowska, and I. Hammar, "Ipsilateral actions of feline corticospinal tract neurons on limb motoneurons," The Journal of Neuroscience, vol. 24, no. 36, pp. 7804-7813, 2004.

[160] E. Jankowska and S. A. Edgley, "How can corticospinal tract neurons contribute to ipsilateral movements? A question with 
implications for recovery of motor functions," Neuroscientist, vol. 12, no. 1, pp. 67-79, 2006.

[161] O. Kiehn, K. A. Quinlan, C. E. Restrepo et al., "Excitatory components of the mammalian locomotor CPG," Brain Research Reviews, vol. 57, no. 1, pp. 56-63, 2008.

[162] K. C. Cowley, E. Zaporozhets, R. A. Joundi, and B. J. Schmidt, "Contribution of commissural projections to bulbospinal activation of locomotion in the in vitro neonatal rat spinal cord," Journal of Neurophysiology, vol. 101, no. 3, pp. 1171-1178, 2009.

[163] J. T. Buchanan and D. R. McPherson, "The neuronal network for locomotion in the lamprey spinal cord: evidence for the involvement of commissural interneurons," The Journal of Physiology, vol. 89, no. 4-6, pp. 221-233, 1995.

[164] P. W. Stubbs and N. Mrachacz-Kersting, "Short-latency crossed inhibitory responses in the human soleus muscle," Journal of Neurophysiology, vol. 102, no. 6, pp. 3596-3605, 2009.

[165] P. W. Stubbs, J. F. Nielsen, T. Sinkjær, and N. Mrachacz-Kersting, "Phase modulation of the short-latency crossed spinal response in the human soleus muscle," Journal of Neurophysiology, vol. 105, no. 2, pp. 503-511, 2011.

[166] P. W. Stubbs, J. F. Nielsen, T. Sinkjr, and N. Mrachacz-Kersting, "Crossed spinal soleus muscle communication demonstrated by H-reflex conditioning," Muscle and Nerve, vol. 43, no. 6, pp. 845-850, 2011.

[167] A. J. T. Stevenson, E. N. Kamavuako, S. S. Geertsen, D. Farina, and N. Mrachacz-Kersting, "Short-latency crossed responses in the human biceps femoris muscle," The Journal of Physiology, vol. 593, no. 16, pp. 3657-3671, 2015.

[168] B. Hanna-Boutros, S. Sangari, A. Karasu, L.-S. Giboin, and V. Marchand-Pauvert, "Task-related modulation of crossed spinal inhibition between human lower limbs," Journal of Neurophysiology, vol. 111, no. 9, pp. 1865-1876, 2014.

[169] V. Stanislaus, C. K. Mummidisetty, and M. Knikou, "Soleus Hreflex graded depression by contralateral hip afferent feedback in humans," Brain Research, vol. 1310, pp. 77-86, 2010.

[170] R. Dubuc, J.-M. Cabelguen, and S. Rossignol, "Rhythmic antidromic discharges of single primary afferents recorded in cut dorsal root filaments during locomotion in the cat," Brain Research, vol. 359, no. 1-2, pp. 375-378, 1985.

[171] J.-P. Gossard, J.-M. Cabelguen, and S. Rossignol, "An intracellular study of muscle primary afferents during fictive locomotion in the cat," Journal of Neurophysiology, vol. 65, no. 4, pp. 914926, 1991.

[172] S. Hochman and D. A. McCrea, "Effects of chronic spinalization on ankle extensor motoneurons. I. Composite monosynaptic Ia EPSPs in four motoneuron pools," Journal of Neurophysiology, vol. 71, no. 4, pp. 1452-1467, 1994.

[173] M.-P. Côté and J.-P. Gossard, "Step training-dependent plasticity in spinal cutaneous pathways," The Journal of Neuroscience, vol. 24, no. 50, pp. 11317-11327, 2004.

[174] M. Knikou, "Plantar cutaneous afferents normalize the reflex modulation patterns during stepping in chronic human spinal cord injury," Journal of Neurophysiology, vol. 103, no. 3, pp. 1304$1314,2010$.

[175] N. J. K. Tillakaratne, R. D. de Leon, T. X. Hoang, R. R. Roy, V. R. Edgerton, and A. J. Tobin, "Use-dependent modulation of inhibitory capacity in the feline lumbar spinal cord," Journal of Neuroscience, vol. 22, no. 8, pp. 3130-3143, 2002.

[176] K. Sadlaoud, S. Tazerart, C. Brocard et al., "Differential plasticity of the GABAergic and glycinergic synaptic transmission to rat lumbar motoneurons after spinal cord injury," The Journal of Neuroscience, vol. 30, no. 9, pp. 3358-3369, 2010.
[177] W. F. Windle, J. O. Smart, and J. J. Beers, "Residual function after subtotal spinal cord transection in adult cats," Neurology, vol. 8, no. 7, pp. 518-521, 1958.

[178] E. Eidelberg, J. G. Walden, and L. H. Nguyen, "Locomotor control in macaque monkeys," Brain, vol. 104, no. 4, pp. 647663, 1981.

[179] P. W. Nathan, "Effects on movement of surgical incisions into the human spinal cord," Brain, vol. 117, no. 2, pp. 337-346, 1994.

[180] F. M. Bareyre, M. Kerschensteiner, O. Raineteau, T. C. Mettenleiter, O. Weinmann, and M. E. Schwab, "The injured spinal cord spontaneously forms a new intraspinal circuit in adult rats," Nature Neuroscience, vol. 7, no. 3, pp. 269-277, 2004.

[181] G. Courtine, B. Song, R. R. Roy et al., "Recovery of supraspinal control of stepping via indirect propriospinal relay connections after spinal cord injury," Nature Medicine, vol. 14, no. 1, pp. 6974, 2008.

[182] R. van den Brand, J. Heutschi, Q. Barraud et al., "Restoring voluntary control of locomotion after paralyzing spinal cord injury," Science, vol. 336, no. 6085, pp. 1182-1185, 2012.

[183] E. S. Rosenzweig, G. Courtine, D. L. Jindrich et al., "Extensive spontaneous plasticity of corticospinal projections after primate spinal cord injury," Nature Neuroscience, vol. 13, no. 12, pp. 15051510, 2010.

[184] J. R. Flynn, B. A. Graham, M. P. Galea, and R. J. Callister, "The role of propriospinal interneurons in recovery from spinal cord injury," Neuropharmacology, vol. 60, no. 5, pp. 809-822, 2011.

[185] L. Filli and M. E. Schwab, "Structural and functional reorganization of propriospinal connections promotes functional recovery after spinal cord injury," Neural Regeneration Research, vol. 10, no. 4, pp. 509-513, 2015.

[186] R. Vavrek, J. Girgis, W. Tetzlaff, G. W. Hiebert, and K. Fouad, "BDNF promotes connections of corticospinal neurons onto spared descending interneurons in spinal cord injured rats," Brain, vol. 129, no. 6, pp. 1534-1545, 2006.

[187] M. M. Rank, J. R. Flynn, C. R. Battistuzzo, M. P. Galea, R. Callister, and R. J. Callister, "Functional changes in deep dorsal horn interneurons following spinal cord injury are enhanced with different durations of exercise training," The Journal of Physiology, vol. 593, no. 1, pp. 331-345, 2015.

[188] P. W. Nathan and M. C. Smith, "Fasciculi proprii of the spinal cord in man: review of present knowledge," Brain, vol. 82, no. 4, pp. 610-668, 1959.

[189] D. Burke, J. M. Gracies, D. Mazevet, S. Meunier, and E. PierrotDeseilligny, "Non-monosynaptic transmission of the cortical command for voluntary movement in man," The Journal of Physiology, vol. 480, no. 1, pp. 191-202, 1994.

[190] E. Pierrot-Deseilligny, "Propriospinal transmission of part of the corticospinal excitation in humans," Muscle and Nerve, vol. 26, no. 2, pp. 155-172, 2002.

[191] J. M. Gracies, S. Meunier, and E. Pierrot-Deseilligny, “Evidence for corticospinal excitation of presumed propriospinal neurones in man," The Journal of Physiology, vol. 475, no. 3, pp. 509518, 1994.

[192] E. Pierrot-Deseilligny, “Transmission of the cortical command for human voluntary movement through cervical propriospinal premotoneurons," Progress in Neurobiology, vol. 48, no. 4-5, pp. 489-517, 1996.

[193] C. Iglesias, J. B. Nielsen, and V. Marchand-Pauvert, "Corticospinal inhibition of transmission in propriospinal-like neurones during human walking," European Journal of Neuroscience, vol. 28, no. 7, pp. 1351-1361, 2008. 
[194] G. Scivoletto, F. Tamburella, L. Laurenza, C. Foti, J. F. Ditunno, and M. Molinari, "Validity and reliability of the 10-m walk test and the 6-min walk test in spinal cord injury patients," Spinal Cord, vol. 49, no. 6, pp. 736-740, 2011.

[195] M. Alcobendas-Maestro, A. Esclarín-Ruz, R. M. Casado-López et al., "Lokomat robotic-assisted versus overground training within 3 to 6 months of incomplete spinal cord lesion: randomized controlled trial," Neurorehabilitation and Neural Repair, vol. 26, no. 9, pp. 1058-1063, 2012.

[196] N. J. Postans, J. P. Hasler, M. H. Granat, and D. J. Maxwell, "Functional electric stimulation to augment partial weightbearing supported treadmill training for patients with acute incomplete spinal cord injury: a pilot study," Archives of Physical Medicine and Rehabilitation, vol. 85, no. 4, pp. 604-610, 2004.

[197] B. Dobkin, H. Barbeau, D. Deforge et al., "The evolution of walking-related outcomes over the first 12 weeks of rehabilitation for incomplete traumatic spinal cord injury: the multicenter randomized spinal cord injury locomotor trial," Neurorehabilitation and Neural Repair, vol. 21, no. 1, pp. 25-35, 2007.

[198] E. C. Field-Fote and K. E. Roach, "Influence of a locomotor training approach on walking speed and distance in people with chronic spinal cord injury: a randomized clinical trial," Physical Therapy, vol. 91, no. 1, pp. 48-60, 2011.

[199] S. Anwer, A. Equebal, T. J. Palekar, M. Nezamuddin, O. Neyaz, and A. Alghadir, "Effect of locomotor training on motor recovery and walking ability in patients with incomplete spinal cord injury: a case series," Journal of Physical Therapy Science, vol. 26, no. 6, pp. 951-953, 2014.

[200] K. J. Manella, J. Torres, and E. C. Field-Fote, "Restoration of walking function in an individual with chronic complete (AIS A) spinal cord injury," Journal of Rehabilitation Medicine, vol. 42, no. 8, pp. 795-798, 2010. 

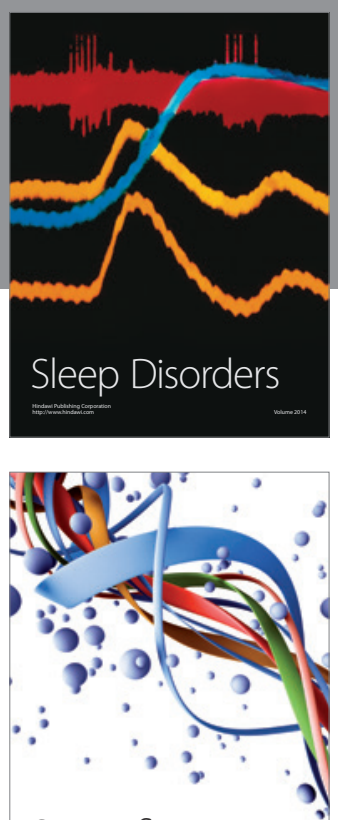

Scientifica
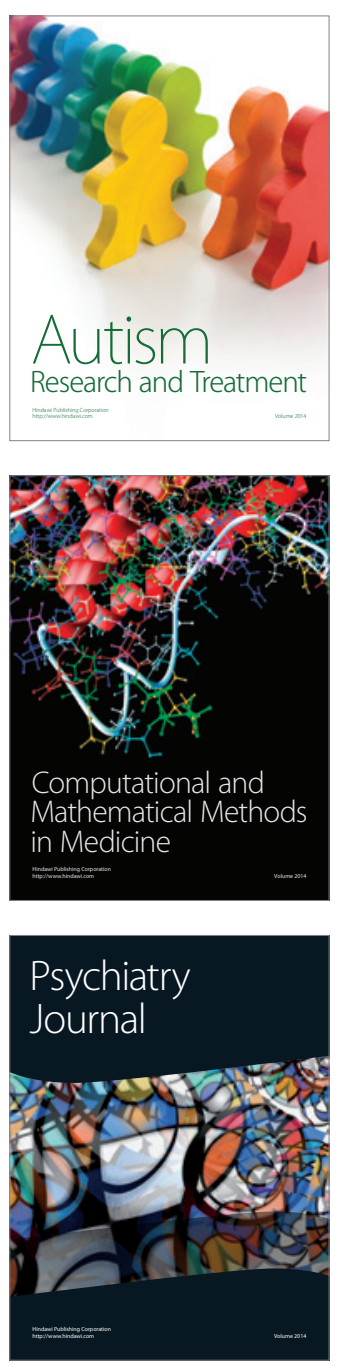
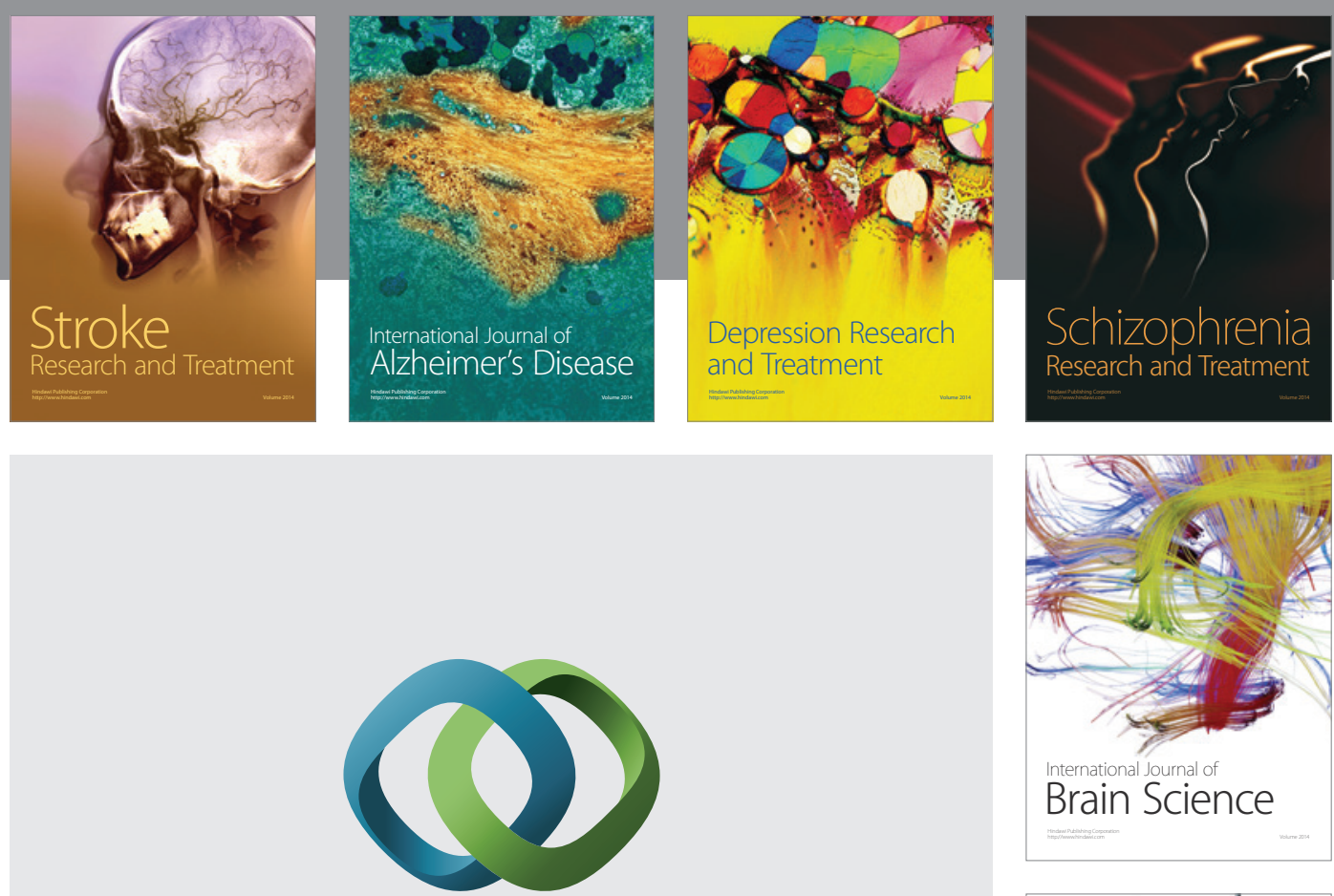

\section{Hindawi}

Submit your manuscripts at

http://www.hindawi.com
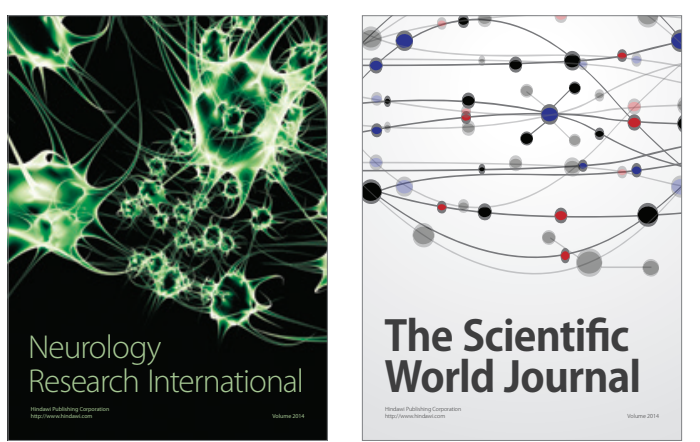

The Scientific World Journal

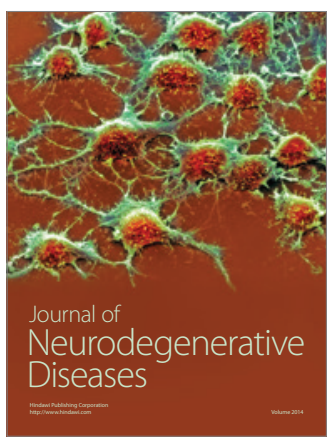

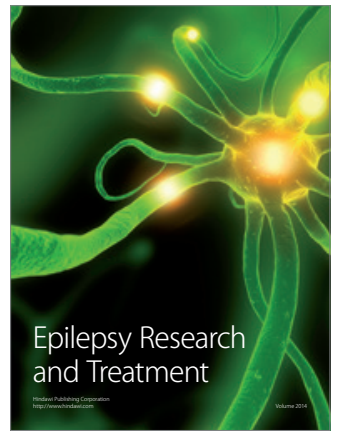

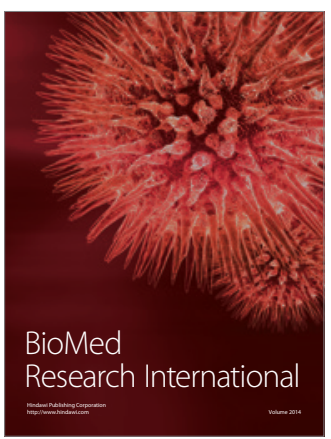

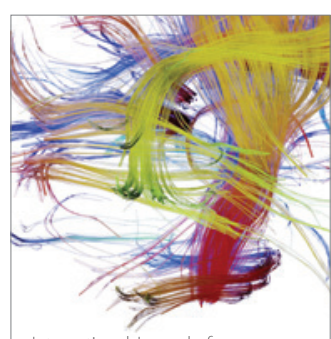

Brain Science

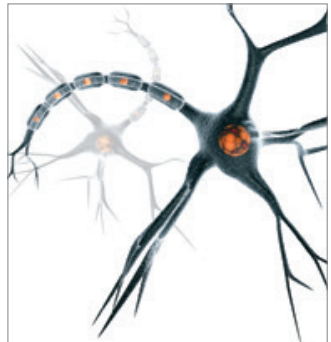

Neural Plasticity
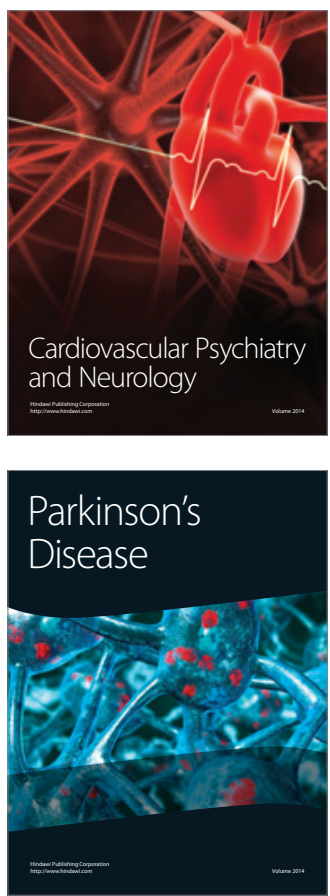